San Jose State University

SJSU ScholarWorks

Master's Theses

Master's Theses and Graduate Research

Spring 2013

\title{
Outcomes of a Recreation Therapy Yoga Meditation Intervention on Prison Inmates' Spiritual Well-Being
}

Kim Hoang Pham

San Jose State University

Follow this and additional works at: https://scholarworks.sjsu.edu/etd_theses

\section{Recommended Citation}

Pham, Kim Hoang, "Outcomes of a Recreation Therapy Yoga Meditation Intervention on Prison Inmates' Spiritual Well-Being" (2013). Master's Theses. 4307.

DOI: https://doi.org/10.31979/etd.6psa-b5hd

https://scholarworks.sjsu.edu/etd_theses/4307

This Thesis is brought to you for free and open access by the Master's Theses and Graduate Research at SJSU ScholarWorks. It has been accepted for inclusion in Master's Theses by an authorized administrator of SJSU ScholarWorks. For more information, please contact scholarworks@sjsu.edu. 
OUTCOMES OF A RECREATION THERAPY YOGA MEDITATION

INTERVENTION ON PRISON INMATES' SPIRITUAL WELL-BEING

\author{
A Thesis \\ Presented to \\ The Faculty of the Department of Hospitality Management and \\ the Department of Health Science and Recreation \\ San José State University
}

\author{
In Partial Fulfillment \\ of the Requirements for the Degree \\ Master of Science
}

by

Kim Hoang Pham

May 2013 
(C) 2013

Kim Hoang Pham

ALL RIGHTS RESERVED 
The Designated Thesis Committee Approves the Thesis Titled

OUTCOMES OF A RECREATION THERAPY YOGA MEDITATION

INTERVENTION ON PRISON INMATES' SPIRITUAL WELL-BEING

by

Kim Hoang Pham

APPROVED FOR THE DEPARTMENT OF HEALTH SCIENCE AND RECREATION

SAN JOSÉ STATE UNIVERSITY

May 2013

Dr. Tsu-Hong Yen Department of Hospitality, Tourism, and Event Management

Dr. Susan Ross Department of Health Science and Recreation

Billie Jo Grosvenor Department of Health Science and Recreation 


\begin{abstract}
OUTCOMES OF A RECREATION THERAPY YOGA MEDITATION INTERVENTION ON PRISON INMATES' SPIRITUAL WELL-BEING
\end{abstract}

\author{
by Kim Hoang Pham
}

The purpose of this research was to analyze a recreation therapy yoga meditation intervention, the Sanatana Yoga Prison Project (SYPP), at a California state prison. The SYPP had three interventions: pranayama (breathing techniques), asana (physical postures), and dhyana (meditation). The research question was, "What are the outcomes of a recreation therapy yoga meditation intervention on prison inmates' spiritual well-being?" This study used a mixed-method approach that included a modified Spiritual Well-Being Scale (SWBS), demographic data sheet, and semistructured interviews that were face-to-face and audio-recorded. There were 31 participants in the control group and 31 participants in the experimental group. Spiritual Wellbeing (SWB) scores were analyzed using the SWBS manual and SPSS 20. The results indicated significant difference between the groups. That is, the experiment group scored high on SWB compared to the control group that scored moderate on SWB. Ten interviews from the experimental group were analyzed using an existentialphenomenological approach. Two overarching categories emerged with four themes each: (a) concrete outcomes with themes of physical benefits, escape, quieting the mind, and reflection, and (b) psychospiritual development outcomes with themes of epiphany, connection to self and others, psychological and behavioral change, and coping skills. 


\section{ACKNOWLEDGEMENTS}

I could not have asked for a better team and support system. My deepest gratitude goes to my mentor, Dr. Susan Ross. If it were not for her guidance, I would have never discovered my calling to Recreation Therapy. I owe my deepest thanks to Dr. Tsu-Hong Yen, Billie Jo Grosvenor, Dr. Randy Virden, Dr. Kim S. Uhlik, Dr. Kelly Bloom, Dr. Ted Butryn, Dr. Jessica Chin, and other faculty members who have taught and inspired me throughout my graduate studies in Recreation. This thesis would also have not been possible if I did not have my colleague and partner in crime, Swapan Munshi. He has worked along my side to see through the great importance of yoga meditation for people's spiritual well-being. I also want to extend my appreciation to all of colleagues,

family, and friends who have contributed in so many ways to support me throughout this tumultuous journey that began with a great idea, and have ended with great success and achievement. Lastly, I want to give thanks to those who have inspired me to bring the phenomenon of spiritual well-being through leisure, towards the frontier of Recreation Therapy. This is just the beginning.

I would like to dedicate this thesis research to the inmates that have graced me with their journey about their worst of times to being able to overcome them because they have been able to discover their spiritual well-being through the SYPP. You all are aweinspiring and I wish you nothing but the best of luck and well wishes on your next chapter in this lifetime.

Thank you Imara for bestowing this beautifully written imprint upon my soul. 


\section{You Were...}

Like pristine air suspended above a mountainous region

Like life-giving rain that feel in season

Like a vision of what the future may bring

Like a captivating rose cradled by the hands of spring

Like light that dispels the darkness, inviting a poorly informed society to see...

to behold the curative effects of recreational therapy;

as it pertains to the psyche of the disenfranchised members of humanity

Like a helping hand...extended. That dared to thrust itself into the bowels of hell.

Like the voice of hopes, declaring convincingly: "All is well."

The absence of your presence has upon my heart undoubtedly taken its toll...

Thank you for being such an "extraordinary" sign,

'O Beautiful Soul

Written by "Imara"

February 10, 2013

Inspired by Kim Pham 


\section{TABLE OF CONTENTS}

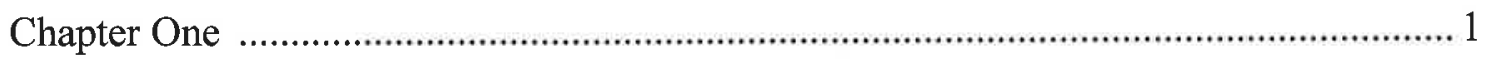

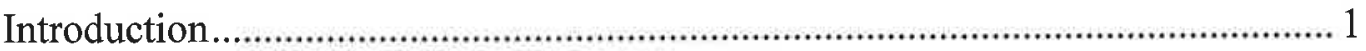

Rationale for study ............................................................................

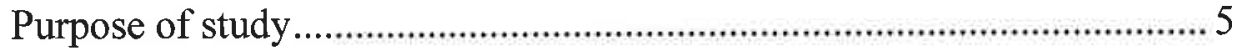

Research question .................................................................................. 6

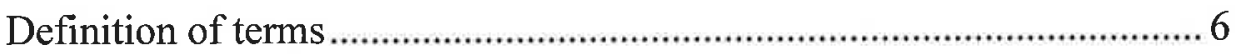

Structure of thesis .................................................................................

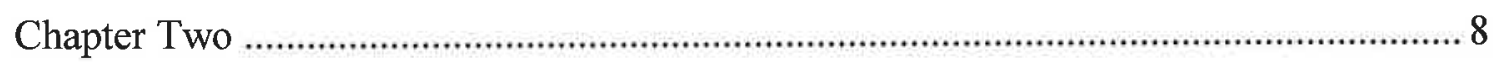

Literature Review.........................................................................................

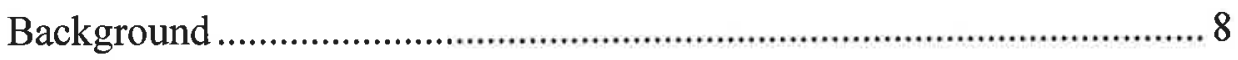

History of spirituality in research ……...................................... 8

History of meditation and yoga in the West .................................. 9

Spirituality in research today ....................................................... 10

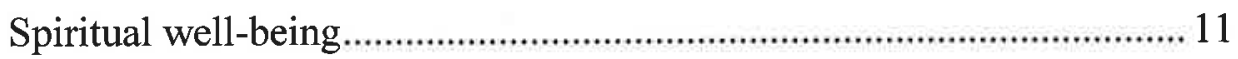

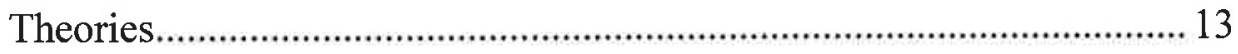

Restorative environments and being away .................................. 13

Benefits of restorative environments ............................................ 14

Spiritual-based work environment .............................................. 15

Negotiosissium Ottium ............................................................... 16

Spiritual coping ......................................................................... 16

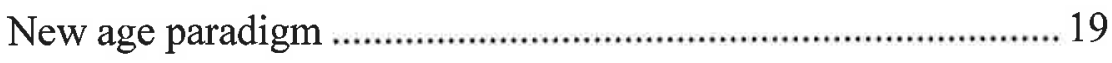


Keeping Idle Hands Busy Theory .................................................2 20

Settings related to spiritual growth through leisure ……........................ 21

Spiritual interventions and outcomes in health care ............................... 22

Spiritual-related interventions in health care …….................................... 23

Spiritual-related interventions in recreation therapy....................2 24

Spiritual-related interventions in prisons .....................................2 29

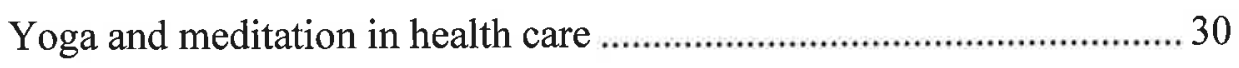

Yoga and meditation in recreation therapy ............................................... 33

Spiritual interventions and recreation therapy in prisons ............. 34

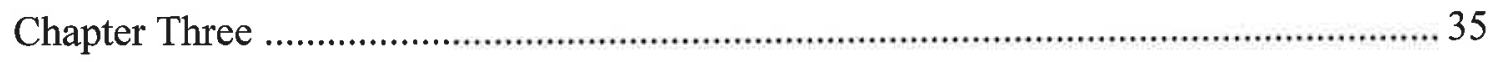

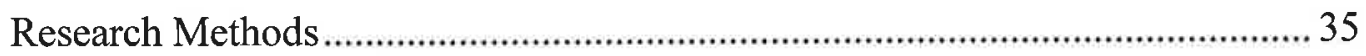

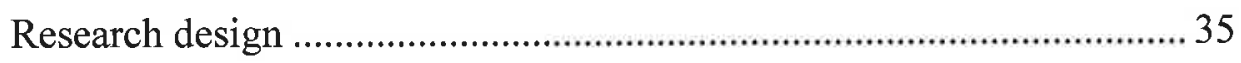

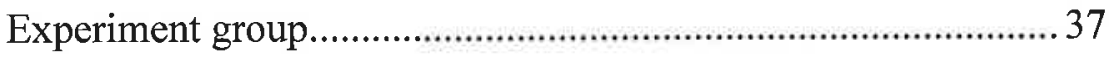

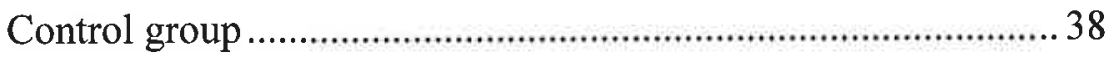

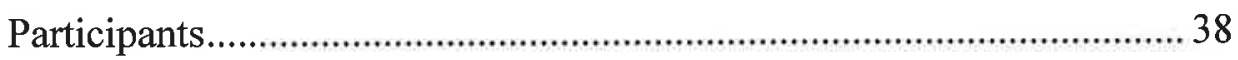

Population and sample size......................................................... 38

Recruitment of participants........................................................ 39

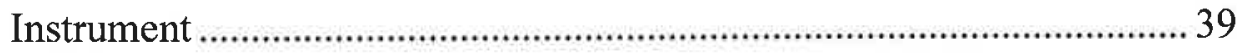

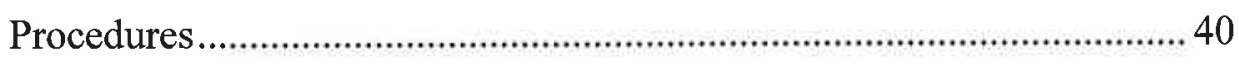

Institutional Review Board ....................................................... 41

Confidentiality............................................................. 42

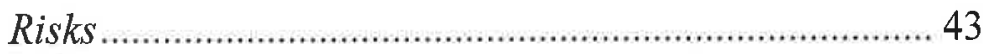


Data collection procedures............................................................. 44

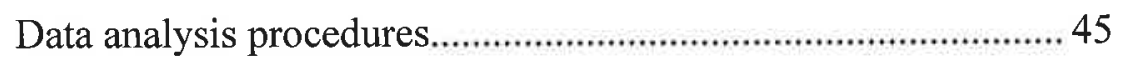

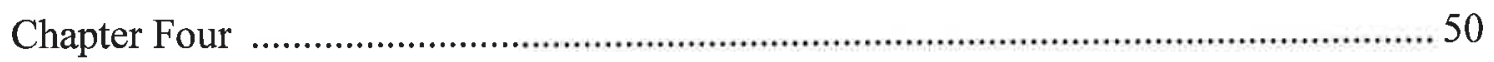

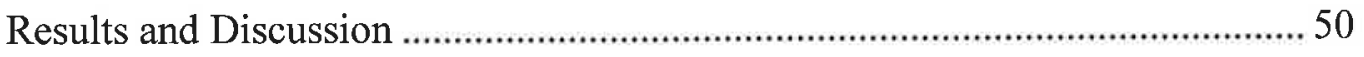

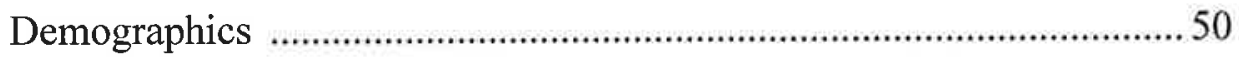

Analysis of the SWBS Scores ................................................................52

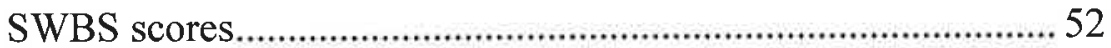

Effects of demographics on SWBS scores....................................53

Analysis of Interviews from Experiment Group...................................... 57

Concrete outcomes ................................................................... 57

Physical benefits ............................................................... 57

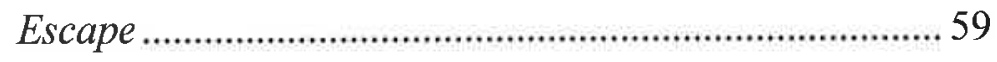

Quieting the mind ........................................................... 60

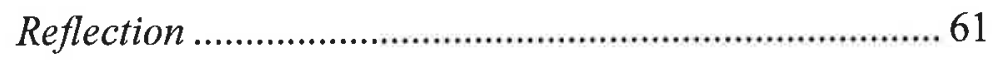

Psychospiritual Development .................................................... 63

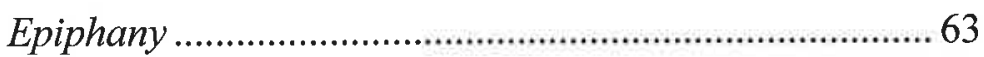

Connection with self and others......................................... 65

Psychological and behavioral change ............................. 67

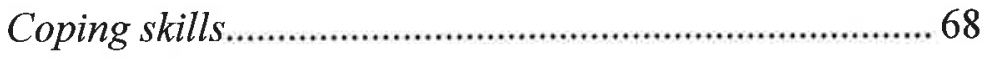

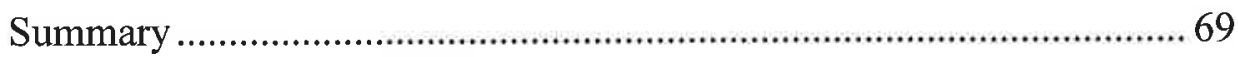

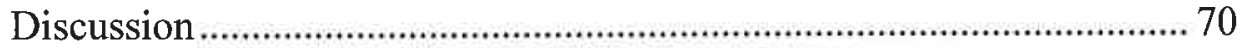

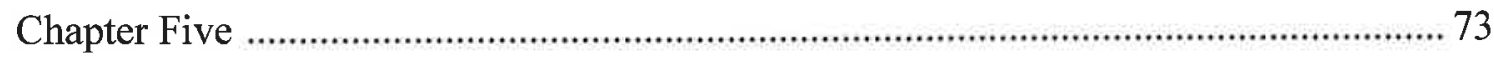


Conclusion and Recommendations................................................................... 73

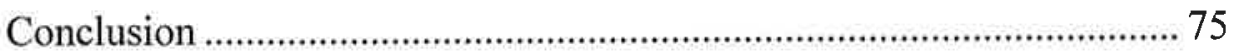

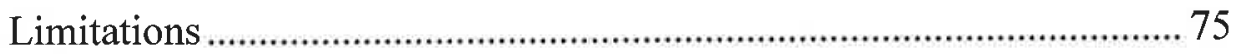

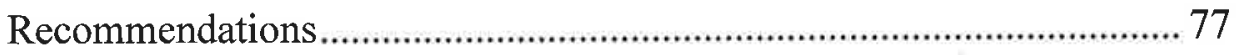

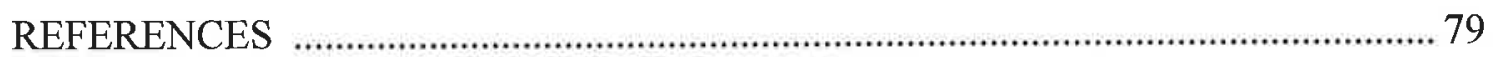

APPENDIX A: Modified Spiritual Well-Being Scale _................................................. 87

APPENDIX B: Demographic Data Sheet................................................................... 88

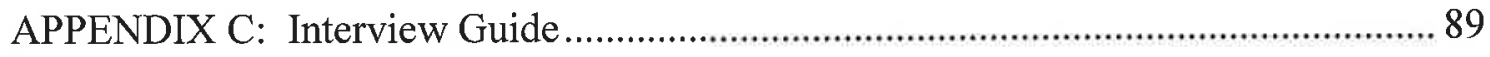

APPENDIX D: SYPP Invitational Flyers.................................................................... 90

APPENDIX E: SJSU Informed Consent Form............................................................ 92

APPENDIX F: CPHS Informed Consent Form............................................................. 94

APPENDIX G: Participant's Bill of Rights for Non-Medical Research ........................99

APPENDIX H: Inmate Declaration to News Media Contact ........................................ 101

APPENDIX I: Warden's (2011-2012) Letter of Support ............................................. 102

APPENDIX J: Warden's (2012-2013) Letter of Support ........................................... 103

APPENDIX K: State of California: Department of Corrections and Rehabilitation

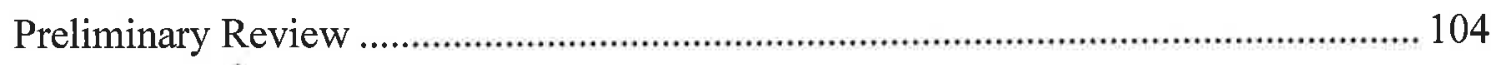

APPENDIX L: California Department of Corrections and Rehabilitation Research

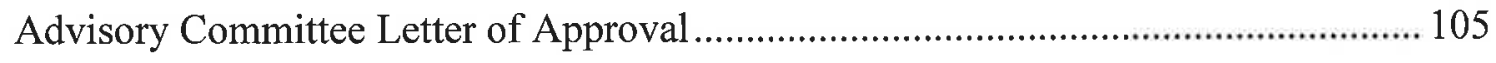

APPENDIX M: Committee for the Protection of Human Subjects Approval Letter.. 106 APPENDIX N: SJSU's Human Subjects-IRB Letter of Approval ............................ 107 


\section{LIST OF TABLES}

Table 1

Score Levels of the Modified SWBS........

Table 2

Subjects' Demographic Information ..... 51

Table 3

Comparisons of the Modified SWBS Scores between Experiment Group and Control

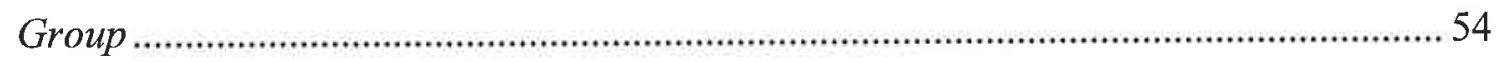

Table 4

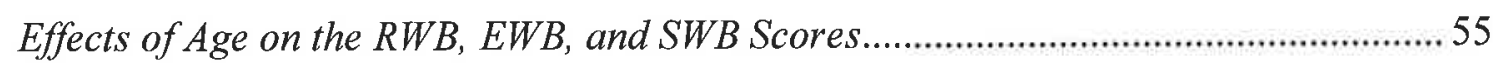

Table 5

Effects of Time Incarcerated on the RWB, EWB, and SWB Scores............................. 56

Table 6

Summary of Experiment Group 's Interview Outcomes ............................................. 58 


\section{Chapter One}

\section{Introduction}

This section provides an overview and rational for the study. Spirituality, health care services, and research on spiritual interventions are discussed to provide a foundation about how this study was developed. This will lead to the purpose of the study, the research question, and definition of terms.

Rationale for study. Historically, spirituality and religion have been considered mutually inclusive because there was no clear understanding between the two factors (Zinnbauer, et al., 1997). However, beginning in the early 21 st century, a growing interest in spirituality (Bliss, 2009; Grant, 2007) as a concept separate from religion(s) in the Western world was developed (Baetz, Bowen, Jones, \& Koru-Sengul, 2006). This divergence of religion(s) and spirituality has become more prominent today because of

the increased recognition of spirituality as an important component to overall mind, body, and spiritual well-being.

To further explain these distinctions, religion is defined as an organized group who concentrate on a set of beliefs, rituals, and practices (Vohra-Gupta, Russell, \& Lo, 2007). Religion also has boundaries and principles. Conversely, spirituality is based on subjective phenomena. It has no limitations due to its individualistic nature, its guidance towards purpose seeking, and its source of healing for people (Vohra-Gupta, Russell, \& Lo, 2007).

There is growing interest in the application of clinical interventions that address spiritual health (Grant, 2007), and there are increased patient requests that spiritual health 
be included in treatment (Schulz, 2005). Many health care professionals have long recognized that spirituality is an important part of many people's overall well-being (Heintzman \& Mannell, 2003; Parry, 2009), yet it appears that few clinical practitioners actually provide spiritual interventions because of a lack of training and education (Belavich, \& Paragment, 2002).

More specifically, there is less understanding about the clinical application of the spiritual dimensions of leisure (Heintzman \& Mannell, 2003; Parry, 2009; Schmidt \& Little, 2007). "Spirituality, religion and their place in medicine [or healthcare] are currently much discussed, to the point where this relationship has been called 'the new frontier" "(Grant, 2007, p. 207).

Due to the increased awareness of spirituality (Bliss, 2009; Grant, 2007), some patients demand that the health care system should include spirituality in their treatments (Schulz, 2005) and that "treatment [should be] designed to focus on spiritual issues [that] may help facilitate outcomes by providing individuals with a higher degree of optimism and hope for improved health" (Groff, Battaglini, Sipe, O’Keefe, \& Peppercorn, 2009, p. $342)$.

Furthermore, many patients are dissatisfied with their medical care despite the expensive equipment and advance technology used (Grant, 2007). Patients have reported health care to be remote, insensible, and more focused on machines and statistics instead of patients' well-being (Grant, 2007). As a result, these patients have felt their treatments are impersonal and, at times, failing in disease prevention or cure. This dissatisfaction 
has led to a higher demand for alternative medicine as treatment across the world (Nagla, 2006).

Spiritual-focused treatments are more personable and individualized to patients' needs, which make them more effective for patients' healing to occur. Ignoring the spiritual dimension in treatments may leave patients feeling incomplete and ignored, which has the potential to interfere with the patients' healing process (Grant, 2007). Clearly, more research needs to be conducted to address this need.

With this "new frontier" of health care reaching prominence, recreation therapists are the ideal professionals to lead this spirituality movement. Recreation therapy practices have a holistic perspective that includes biopsychosocial factors and spirituality (Richeson, personal communication, October 7, 2010). For example, leisure and recreation interventions help patients discover themselves and find meaning and purpose in life. Richeson (2010) found these interventions to be related to spirituality because it connected the human's emotional needs to a true self. Recreation therapy is particularly suited to meet these needs by facilitating services that teach the ways in which "leisurespiritual coping can promote mental health through...adapting to and transcending life challenges" (Heintzman, 2008, p. 69).

Although an increase in demand for spiritual interventions in health care is evident, there is a lack of research about the relationship between leisure, spiritual coping, and spiritual well-being (Heintzman \& Mannell, 2003; Parry, 2009). Furthermore, there is also a lack of understanding of spirituality as a coping method to negative stressors in life (Heintzman, 2009, 2010; Mystakidou, et al., 2008); therefore, 
many researchers have recommended more studies to be conducted on how leisure contributes to individuals' spiritual well-being (Heintzman, 1999, 2000, 2002; McDonald \& Schreyer, 1991; Schmidt \& Little, 2007).

With this lack of research and understanding, it is plausible to understand why many recreation therapists are hesitant to explore spirituality with patients (Mystakidou, et al., 2008; Richeson, personal communication, October 7, 2010). It is possible that practitioners lack the skills and/or confidence to facilitate spiritual interventions; additionally, they might not perceive the importance of spirituality in clients' overall well-being due to lack of training and understanding (Belavich \& Paragment, 2002; Grant, 2007; Heintzman \& Mannell, 2003).

Moreover, spirituality is a subjective, complex phenomenon, which makes it difficult to understand (Richeson, 2007, Schulz, 2005). Recreation therapists can contribute to client's well being if they had a better understanding of the relationship between leisure and spirituality (Heintzman \& Mannell, 2003); however, many recreation therapists still struggle with how to document spiritual experiences, so they minimize, if not totally ignore, the importance of such an experience that can provide a means of coping with a traumatic illness or experience (Howe-Murphy \& Murphy, 1987).

More research needs to be conducted especially in the field of Recreation Therapy because there is still very little research on implementation of spiritual interventions (Howe-Murphy \& Murphy, 1987). More research on the use of spirituality through recreation therapy would not only contribute to recreation therapy, but it would 
also help develop and improve spirituality models, facilitation, and treatments (Heintzman, 2008).

The importance of having an abundance of research reiterates the importance of evidence-based practices and standardization, which can lead to improving clients' wellbeing and the profession in health care (Stumbo, 2009). There have been a number of theoretical studies conducted on spirituality and leisure, but it is recommended to apply this knowledge to specific leisure activities to better understand the outcomes and benefits (Heintzman, 2009, 2010; Parry, 2009) and adverse effects (Heintzman, 2009, 2010; Mystakidou, et al., 2008).

Research on the relationship between leisure and spirituality has looked only at specific types of settings as catalysts for spiritual experience: nature (Heintzman, 2002, 2008 2009, 2010; Schmidt \& Little, 2007), wilderness (Griffin \& LeDuc, 2009;

Heintzman \& Mannell, 2003; Heintzman, 2010; Stringer \& McAvoy, 1992), camping (Griffin \& LeDuc, 2009; Heintzman, 2010; Henderson, Oakleaf, \& Bialescki, 2009, Sweatman \& Heintzman, 2004), and outdoor recreation (Heintzman, 2010; Parry, 2009; Peace, 2009). Meditation and yoga are in one category of leisure that has yet to be thoroughly explored in the recreation and leisure science literature (Francis, 1991).

Purpose of study. The purpose of this research was to analyze a recreation therapy intervention on a yoga meditation program called the Sanatana Yoga Prison Project (SYPP) at a California prison to determine whether the participants experienced outcomes of spiritual well-being, which may or may not have been due to participating in three interventions: (a) pranayama (breathing exercises), (b) chakra meditation, and (c) 
yoga. The goal was to contribute to the scholarly discourse in the field of recreation therapy and to produce preliminary outcomes data by clarifying the spiritual aspects of interventions specifically designed and facilitated to affect spiritual health and wellbeing.

Research question. The research question is: "What are the outcomes of a Recreation Therapy meditation yoga intervention on prison inmates' spiritual wellbeing?" This question is informed by literature and is designed to update current practice.

Definition of terms. Within this section, four terms are clearly defined for clarification of their use within the context of this research. These four terms are (a) spiritual well-being, (b) meditation, (c) sacralization, and (d) yoga.

Spiritual well-being is defined as an integral part of mental, physical, emotional and overall health or well-being (Gomez \& Fisher, 2003; Heintzman, 2002; Heintzman \& Mannell, 2003). It is the discovery of one's purpose and meaning in life and it is considered a coping mechanism (Casa Palmira Treatment Center, 2013). It interrelates five attributes: finding meaning and purpose in life, values, transcendence beyond oneself, connection with self, others, God/Spirit/Divine, and nature (Martsolf \& Mickley, 1998).

Meditation is using mind-focus skills to become in a self-induced state of mind and awareness to achieve relaxation, peace, concentration, and clarity (Bond, Ospina, Hooton, Bialy, Dryden, Buscemi, Shannahoff-Khalsa, Dusk, \& Carlson, 2009; Derezotes, 2000). Some scholars say it is a mindset of spiritual contemplation (Vohra-Gupta, 
Russell \& Lo, 2007). This fosters spiritual development through the process of sacralization (Heintzman, 2008).

The third term, sacralization, is identified by Heintzman and Mannell (2003) as a spiritual function of leisure, although Heintzman $(2002,2008)$ defined it as sensitivity to the spiritual dimension of life. It is also understood as the "use of leisure for nurturing the spiritual dimensions of life, and use of leisure to provide the time and space to develop spirituality" (Parry, 2009, p. 213).

Finally, yoga is a practice or coping activity that involves breathing exercises, simple stretches, and postures designed to strengthen and relax the musculoskeletal system (Chiesa, \& Serretti, 2009), which altogether encourages concentration or focus of one's attention (Heintzman, 2008) although uniting the individual with a higher being or transcendence (Vhora-Gupta, Russell \& Lo, 2007).

Structure of thesis. This thesis consists of five chapters. Chapter One is the introduction, which sets forth the rationale for this study, the purpose of the study, the research question, the definitions of four research terms, and the research design. Chapter Two reviews literature review that provides a theoretical background, concepts, and framework that will lead to how and why this thesis was developed. Chapter Three introduces the research methods, design, the research participants, instrument, and procedures. Chapter Four presents the results and discussion of the findings from the data collection of this research study. Finally, Chapter Five is composed of the conclusion, limitations, and recommendations of this thesis. 


\section{Chapter Two}

\section{Literature Review}

This chapter is a review of pertinent literature regarding leisure and spiritual wellbeing. This chapter is divided into seven sections. The first introduces research on yoga mediation interventions and spirituality. The second section discusses studies conducted on spiritual well-being. Then, section three will present theories in relation to leisure and spiritualty. Section four will refer to various studies related to spiritual growth through leisure. Section five explores research conducted on spiritual intervention outcomes in health care. Section six describes research findings on yoga and meditation in health care. Finally, section seven presents research on yoga and meditation in Recreation Therapy.

Background. This first section provides an overview of the history of spiritualty, yoga, and meditation. It entails key terminology, concepts, and discussion in relevant literature.

History of spirituality in research. Spirituality has been contemplated for thousand of years, but in years of late, contemporary society requires we study the effects of its practices on human health empirically. For example, publications on the role of spirituality towards healing and health have increased during the 21 st century with over 2000 papers published in the health care literature compared to having very few published before that (Grant, 2007). At the end of the 1980s, many scholars argued about expanding the medical model to include spirituality because it is a fundamental determinant of psychological, physical, and social variables (Mystakidou, et al., 2008). 
Spirituality has become an important necessity for healing among patients in medical and mental-health settings. Patients have requested spirituality to be included in health care settings and treatments (Schulz, 2005). It has been have suggested that spirituality is on the verge of playing a strong role in the healing process and achieving optimal well-being (Belavich \& Paragment, 2002; Bellamy, et al., 2007; Gomez \& Fisher, 2003; Grant, 2007; Griffin \& LeDuc, 2009; Heintzman, 2008, 2009, 2010; Parry, 2009; Peace, 2009; Schmidt \& Little, 2007; Schulz, 2005; Stringer \& McAvoy, 1992). Although literature related to leisure sciences has discussed the importance of spirituality and the linkage between leisure and spirituality and the linkage between leisure and spirit since before the times of Plato and Aristotle, it has not been until recent times that leisure research has attempted to study the two empirically. The first article combining leisure and spirituality was published in 1991 (Heintzman, 2009). Meditation and yoga have been suggested to have positive benefits towards spiritual well-being (Brown \& Gerbarg, 2005; Brusset \& Brusset, 2000; Groff, Battaglini, O’Keefe, \& Peppercorn, 2009; Iwasaki, 2007).

History of meditation and yoga in the West. Researchers have studied yoga over the past 80 years (Derezotes, 2000). Meditation and yoga are rooted in Eastern cultures such as India, China, and Japan (Derezotes, 2000; Nagla, 2006; Vohra-Gupta, Russell, \& Lo, 2007). Immigration and travel over the past century led to the transmigration of meditation from its Eastern roots within Hindu and Buddhist philosophies. This was the beginning of the evolution of spiritual practice in Western cultures (Vohra-Gupta, Russell, \& Lo, 2007). 
There have also been suggestions that these practices have transitioned into the Western world due to two reasons: (a) the amendment to the immigration law in 1965 and, (b) the Baby boomers and Generation X (Vohra-Gupta, Russell, \& Lo, 2007). Buddhist scholars introduced meditation and yoga by presenting these practices to the World Parliament of Religions in Chicago in late $19^{\text {th }}$ century. By the early $20^{\text {th }}$ century, many Buddhist teachers began opening meditation practice centers in the United States.

Baby Boomers' greatly affected the surged interest in meditation and yoga simply because of their size. The boomers valued and emphasized personal growth and selfactualization; Generation X took this step further, sought the sacred outside of institutionalized religion, and found spirituality. This search led to both of these generations to help expand spirituality beyond the bounds of organized religion.

Spirituality in research today. Spirituality is increasingly being recognized as an important component of overall well-being (Heintzman \& Mannell, 2003; Parry, 2009). The vast minority of leisure scholars acknowledges that leisure is related to spiritual experience (McDonald \& Schreyer, 1991). Spiritual aspects of leisure experiences are still under-explored in research.

This opportunity for research is more staggering when we consider that there is a significant relationship between leisure, spirituality, and positive health (Belavich \& Paragment, 2002; Bellamy, et al., 2007; Grant, 2007; Griffin \& LeDuc, 2009; Gomez \& Fisher, 2003; Heintzman, 2008, 2009, 2010; Parry, 2009; Peace, 2009; Schmidt \& Little, 2007; Schulz, 2005; Stringer \& McAvoy, 1992). The Handbook of Religion and Health indicated that there is growing body of research on the significance between 
spiritual/religious commitment and health (Grant, 2007). In fact, there are more than 1,200 studies and 400 research reviews in the 21 st century in the Handbook of Religion and Health.

In recent years, use of the medical model has also shifted its emphasis on the whole person (Gomez \& Fisher, 2003). Yet, this is only the beginning of understanding the relationship between leisure and spiritual well-being. The following literature review will cover various aspects of spirituality as researched in healthcare to better understand the relationship between spiritual well-being and leisure.

Spiritual well-being. Gomez and Fisher (2003) described spiritual well-being as deriving from consciousness and integration among all the dimensions of human relation. It includes the harmony within the dimensions of relationships with oneself (intrapersonal), others (interpersonal), nature (environment), and transcendental other (or dimension). These four domains interrelate to become a person's overall spiritual wellbeing. The first domain refers to how one intra-relates with oneself with regard to meaning, purpose, and values (Gomez \& Fisher, 2003; Heintzman, 2002). The second domain is about the quality and depth of relationships with themselves and others (Gomez \& Fisher, 2003; Heintzman, 2002). The third involves oneness with nature and beauty (Heintzman, 2002), including a sense of awe, wonder, and connection with one's surrounding (Gomez \& Fisher, 2003). Finally, is the relationship of self-connecting with something or someone greater than oneself, such as the divine, a higher being, God(s), and/or the universe (Gomez \& Fisher, 2003; Heintzman, 2002). 
From the perspective of the medical model, health has historically been thought of as the lack of illness. However, over recent decades, "Spiritual well-being is increasingly being recognized as an important component of overall health...physical, social, emotional, mental, and spiritual" (Heintzman \& Mannell, 2003, p. 207). Individuals who are harmonized with these four domains of health are believed to portray a strong spiritual well-being (Heintzman, 2002). Spiritually healthy people show trust, honesty, integrity, altruism, compassion, and service (Hawks, 1994; Heintzman, 2002, 2010) to self, others, and the nature.

Spiritual health is "a high level of faith, hope, and commitment in relation to a well-defined worldview or belief system that provides a sense of meaning and purpose to existence in general, and that offers an ethical path to personal fulfillment which includes connectedness with self, others, and a higher power or larger reality" (Hawks, 1994, p. 6). Heintzman (2002) and Gomez and Fisher (2003) agree that spiritual well-being included a sense of meaning and purpose in life. Both researchers also agree that spirituality involves a sense of love, joy, peace, hope, and fulfillment.

Heintzman (2002) added that spiritual well-being includes a sense of wholeness and strong spiritual beliefs, principles, ethics, and values. Heintzman (2010) took the notion of spiritual well-being further by conducting a comprehensive research on the application of nature-based recreation. The researcher discovered two types of spiritual outcomes: (a) the spiritual experience and (b) the spiritual well-being. The spiritual experience is considered the short-term phenomena with outcomes of peace (Fox, 1997; Sweatman \& Heintzman, 2004; Heintzman, 2007a, 2010), happiness (Fox, 1997; 
Sweatman \& Heintzman, 2004) awe and wonderment, connectedness, heightened sense, joy, elatedness (Fox, 1997). Sweatman and Heintzman (2004) added love and enhanced emotional well-being. The experiences that are considered most spiritual were also identified as the most emotionally intense, and in most cases were positive emotions that led to values and behavioral changes (Heintzman, 2010). Heintzman (2010) included that the spiritual experience created a sense of empowerment and clarity that led to inner strength and self-control, which affected daily life such as work, family, and personal goals. Spiritual well-being is considered a long-term experience. Hawk's (1994) and Heintzman's (2010) explanation of spiritual well-being is congruent with Gomez and Fisher's (2003) and Heintzman's (2002). Heintzman (2010) found that nature-based recreation could produce spiritual well-being.

Theories. This section is a review of relevant theories that involve both leisure and spirituality. Each of these theories contributes to the discourse that attempts to make sense of the spiritual nature of leisure.

Restorative environments and being away. Restorative Environments Theory may help further explain why nature-based recreation is conducive to spiritual wellbeing. It is the notion of getting away or having time-out to have the opportunity to break away from everyday living that has been frequently identified as a means of spiritual or emotional renewal (Heintzman \& Mannell, 2003; Heintzman, 2002, 2008). There are four components: (a) being away, (b) extent (c) fascinations, and (d) compatibility (Heintzman \& Mannell, 2003; Heintzman, 2002). Being Away is a conceptually or physically different setting from one's everyday environment. Extent is referred to as 
duration of leaving a setting that may stimulate the mind to explore. Fascination is a form of effortless attention. Finally, compatibility can help find a person's purposes. Here, individuals reflect on fears, issues, and internal imbalance towards well-being. Another theory that is similar to Restorative Environments Theory is Being Away. Heintzman (2010) suggested that living in or near large urban areas comes with constrictions to one's spirituality, although the wilderness presents a different living environment free from external constraints. Given this assumption, being in a different place is conducive to renewal and restoration. Relief from busyness and obligations by relocating to nature and wide-open spaces helps individuals to become more spiritually grounded and balanced. Heintzman (2009) purports that busyness is detrimental to spiritual well-being and those daily constraints do not allow individuals to be still and to listen to their internal instincts. This listening is necessary to help guide oneself to live a fulfilling and meaningful life.

Benefits of restorative environments. There are a variety of Heintzman (2002) theorizes four benefits of restorative environment. The first is being able to clear the mind of constant racing thoughts that derive from life's external constraints. Second, involves recuperating from fatigued directed attention, which is the ability to focus on something that is not particularly interesting to a person. Third, it is the ability to think about one's unresolved personal issues. Finally, is the space to contemplate life's larger questions such as priorities, goals, and one's purpose. Natural settings tend to encompass all four of these benefits. In contrast, most urban environments lack one or more of these four restorative benefits. 
One of the components of Restorative Environments theory is called fascination. This has two layers: hard fascination and soft fascination. Hard fascination is a characteristic of activities such as those that have extreme intensity, capturing one's attention, and leaving minimal opportunity for one to process his/her thoughts. Sacralization is the experience of when people sense a spiritual dimension (Heintzman, 2002) or a spiritual aspect of their leisure (Heintzman \& Mannell, 2003; Parry, 2009). Fascination is also the..."use of leisure for nurturing the spiritual dimensions of life, and use of leisure to provide the time and space to develop spirituality" (Parry, 2009, p. 213).

Hard fascination is also considered to be a less restorative element for one's spiritual well-being. Examples of hard fascination are urban settings, watching television, watching or participating in sports, and other things that require less active participation and engagement. Soft fascination, on the other hand, is conducive to sacralization because its restorative benefits have moderate intensity towards spiritual well-being. In other words, it has the adequacy to maintain attention without effort, but less intensity that it would prevent reflection. Finally, soft fascination environments are considered pleasant, thereby counterbalancing any fears, issues, or trauma that may be associated with one reflecting on serious negative matters that would be in-conducive to one's spirituality.

Spiritual-based work environment. Gross-Schaefer (2009) expanded other researchers' studies on nature-related environments by conducting research on spiritual well-being in the work setting. Gross-Schaefer shows that spirituality could derive from a spiritually focused work environment. Employees' benefit from this because their 
morale is strengthened when given appreciation and purpose, greater interconnectedness and sense of loyalty, increased self-esteem, more creativity, and good productivity. Increased loyalty reduced theft, fraud, and cheating. Co-workers treated each other in a more respectful and honest manner. Spiritually-focused work settings resulted in employees being physically healthier as evidenced by decreased sick days and less medical bills. Overall, spiritual-focused work settings had healthier employees, which resulted in more productivity and success for the company or work facility.

Negotiosissium Ottium. Negotiosissium Ottium theorized the balance between work and rest (Heintzman \& Mannell, 2003). Busy leisure (i.e., prayers, reading, writing) was found to foster spirituality and tend toward restfulness. Individuals with "impoverished" leisure were less healthy compared to individuals with "rich" leisure (i.e., frequent and varied participation) were healthiest.

Spiritual coping. Another component to spiritual well-being is spiritual coping. Coping is the mechanism used to deal or face an issue or problem at hand. Szalavitz (2010) found two forms of coping: emotion-focused coping and problem-focused coping. Emotion-focused coping is used to modify a person's emotional response to stress and is used when a source of stress is seen as difficult to change in one's favor. Researchers proposed that mindfulness mediation is a form of emotional-focused coping that address stressors such as substance abuse. The second form, problem-focused coping, is directed at modifying sources if it is for the benefit of oneself.

Spiritual coping is a defense mechanism individuals utilize to seek help from spiritual resources such as a higher power, spiritual practices, or faith community during 
periods of life stresses (Heintzman, 2008, 2010) during periods of life stresses. Examples of spiritual coping resources can be connections with nature, others, and/or transcendent other. Spiritual coping generally serves as a mediator between attachment and adjustment to stressful events (Belavich \& Paragment, 2002). Belavich and Paragment (2002) found that individuals who employed spiritual coping had a positively significant adjustment to stressors. Various coping styles may have provided individuals with a sense of control, which in other words provided a sense of security during a time of trauma. Furthermore, this study revealed that research participants used spirituality in coping with a wide variety of events: raising a child who is handicapped, having cancer, experiencing widowhood, and/or dealing with daily life's hassles (Belavich \& Paragment, 2002).

According to Heintzman (2008), spirituality serves as an important source for coping. This is a set pattern of expected occurrences when faced with a stressor(s). The researcher found that leisure might have outcomes of spiritual coping that helped alleviate, overcome, and transcend many stresses and challenges. The Spiritual Framework of Coping was also found to be applicable to different faiths and cultural traditions. Heintzman (2008) suggests that spiritual beliefs and values initially determine one's ability to make sense of the stressor(s) and to gain stability during the turbulence. For example, an individual would rely on coping behaviors common to their religion such as praying and having faith in God's hands to resolve the issue. Individuals may also engage in various types of spiritual behaviors such as prayers, religious ceremonies and services, and nontraditional and spiritual practices (Heintzman, 2008). Heintzman (2008) 
recommended that Recreation Therapy interventions and programs should include spiritual renewal seminars/retreats, spiritual health support cases, spiritual health oriented lending libraries, and spiritual health workshops.

Belavich and Paragment (2002) on the other hand, suggest three styles of spiritual coping in response to stressors: (a) self-directed, (b) deferring, and (c) collaborative coping style. The self-directed coping reflected the belief that it is an individuals' own responsibility to solve his or her problems and that the divine has minor direct influence in the process because of one's free will in life. This has shown to be successful in many types of situations, but it has also shown disadvantages in uncontrollable situations such as immanent death due to illness. Some may choose to defer and wait for a solution to emerge through the divine. This has been found to be more helpful in situations that are beyond the individual's control. Finally, collaborative coping style is based on the individual's decision to share responsibility with the divine to solve the problem(s). This is the only style that has shown consistent significance to spiritual coping.

Spiritual well-being is another form of spiritual coping because the connection with others, nature, and the divine allows individuals to cope with stressors. Individuals will make meaning of the stressor and be able to find significance to life's purpose, growth, and transformation. This may lead to a reappraisal of beliefs and an attitude of being concerned of oneself, others, and/or the universe.

Leisure is another form of spiritual coping because it relieves stress. Leisurespiritual coping is a type of stress management within the context of an individual's leisure (Heintzman, 2008). For example, the connection with nature has been identified 
as a leisure-spiritual coping resource. Leisure-Spiritual Coping Behavior is the behavior of coping through leisure that involves a variety of emotion and problem-centered strategies (Heintzman, 2008). Heintzman (2008) identified three types coping behaviors. First, organizational religious behavior is the engagement in formal, religious organization, services or activities (i.e., attending or belonging to a church). Private religious or spiritual practice involves studying sacred texts, prayers, watching religious television and singing religious hymns. The final coping behavior used nontraditional spiritual practices such as mental exercises, relaxation techniques, guided imagery or introspection. Bellamy, et al. (2007) also found the same types of leisure-spiritual coping behaviors with people diagnosed a mental illness.

Kirkpatrick $(1992,1994,1999)$ borrowed Bowlby's (1969) theory that explains why individuals choose particular spiritual coping strategies to cope. It also explains why some may reject other coping behaviors when responding to stressful events (Belavich \& Paragment, 2002). This may depend on individuals' attachments to their personal beliefs and values.

A theory on the relationship between spirituality and leisure is called spiritual functions of leisure (SFL). It referred to the way of which leisure can maintain, enhance, or even inhibit spiritual well being (Heintzman \& Mannell, 2003). This spiritual coping mechanism may minimize the negative impact of time pressure on the spiritual wellbeing.

New age paradigm. With the increased interest in spirituality, a phenomenon describes the shift an emerging world view that differs from paradigms that involve 
organized religion. This is also known as the New Age Paradigm. Howe-Murphy and Murphy (1987) were the first to bring this conversation to Recreation Therapy. They explain that the New Age Paradigm requires individuals develop "personal consciousness, leading to a lifestyle of wellness and which incorporated the elements of the mind, body, and spirit, is the essential framework for our quests as therapeutic recreators" (Howe-Murphy \& Murphy, 1987, p. 47). Here, the mind, body, and spirit are inseparable and integrated. This phenomenon needs to be recognized in society because it plays a part in achieving the maximum potential of positive outcomes.

Furthermore, the individual and the environment are interdependent and are mutually influencing each other. The inner consciousness is connected intricately with the global consciousness. In other words, what is done at the immediate micro level, the individual, is transferred into the universe. This paradigm recognized that the nature, direction, and meaning of an individual life are to nurture its spirituality, which has been found to be the key to living a fulfilling life.

Keeping Idle Hands Busy Theory. People are believed to be happiest when they are engaged in an activity. Leisure is a significant component to spiritual well-being because it prevents people from being idle and provides constructive behavioral alternatives to mischief. Keeping the mind busy helps distract individuals from distressing, stressful thoughts (Mannell \& Kleiber, 1997) or worse, thoughts that could be viewed by religion as evil. Non-spiritual activities might reduce spiritual wellness. Leisure involvements allow for reflection or meditation that may elicit introspection and facilitate spiritual well being. 
Settings related to spiritual growth through leisure. One of the most widely studied settings associated with spirituality is in nature and the wilderness (Heintzman, 2008, 2009, 2010; Stringer \& McAvoy, 1992). Heintzman and Mannell (2003) found that a variety of specific settings such as primitive wilderness, non-urban natural areas, quiet urban recreation areas, busy urban recreation areas, and one's own home were all significant to one's spiritual well-being. The expansiveness of the landscape and the consciousness of absolute power was what it brought to the spiritual experience. Nature allows individuals to be free and away from the constraints of modernity. The naturalness allows individuals to "...find inner peace and tranquility, solitude, beauty, and spiritual rekindling..." (Heintzman, 2009, p. 432). Opportunities for internal reflection through contact with nature led to the "appreciation and observation of nature's space, beauty, power, and calmness (Heintzman, 2009).

Stringer and McAvoy (1992) found consistent results with Heintzman and Mannell, but added wilderness adventure participants who were in a different/new setting had an outcome of spiritual well-being as well, which reiterated the theory of Being Away. The researchers also found that there was a sense of connectedness, heightened senses, inner peace and happiness and elatedness (Stringer \& McAvoy, 1992).

Another setting-related theory called Place Process point to the significance of the environment to spirituality (Heintzman, 2010). Place Process is also known as having personal history or a sense of space that is personally meaningful and valuable because it shared a cherished moment(s) that was connected to that setting. The positive emotions and thoughts reminisced were instilled in a specific place significantly correlated with 
spiritual well-being. For example, leisure settings of personal or human history that is associated from childhood or earlier periods of life provided meaningfulness to individuals (Heintzman, 2009).

Another way to explain how certain settings have an effect on spiritual well-being is called triggers (Schmidt \& Little, 2007), which are certain queues, or situations that generate leisure experiences. The researchers found four triggers: (a) nature, (b) newness and difference, (c) challenges, and (d) rituals and traditions. These four triggers are most commonly present when individuals find meaning, purpose in life, and/or discovery of self, others, and the environment.

Newness, novelty or difference referred to experience of doing something new or going somewhere different might help individuals engage with his/her soul. A consistent example of this in the literature is travel. A Nature trigger offers an outlet from constraints and provide instead, an awe-inspiring vista, and a grounding option where they felt freely connected with themselves, the world, and/or divine. A challenge trigger consists of learning something new and pushing one's self towards healthy risks which fosters awareness of others, the surroundings and one's self. Finally, rituals and traditions provide challenge, focused attention, and/or space for interaction. Leisure practices such as meditation, yoga, and T'ai Chi are great examples of rituals and traditions.

Spiritual interventions and outcomes in health care. The literature review that follows will disclose some of the outcomes of spiritual interventions that have been found in the general health care settings, Recreation Therapy, and prisons. The last section of 
the literature review will then focus specifically on what types of outcomes have been found from studying yoga and meditation in health care and Recreation Therapy.

Spiritual-related interventions in health care. Spiritual dynamics found by researchers to derive from engaging in solitude leisure or in groups that make an impact on the outcomes of spiritual well-being (Bellamy, et al., 2007; Heintzman, 2002, 2008, 2010; Stringer \& McAvoy, 1992). For example, Bellamy, et al. (2007) and Heintzman $(2002,2010)$ found that social activities developed spiritual well-being and connectedness with others.

Stringer and McAvoy (1992) also found that shared experiences with others to be crucial to spiritual experience. Conversely, solitude and solitary activities provide time and space that is conducive to developing spiritual well-being and finding purpose and meaning (Heintzman, 2002, 2010). Individuals with high levels of social support and self-determination are less likely to experience intensive debilitation in the event of trauma or loss such as death of a loved one, near-death-experience(s), or grave suffering (Heintzman, 2002). On the other hand, solitude activities create awareness and appreciation for nature's beauty and awe. Bellamy, et al., (2007) found that reading and social activities had the highest correlations with perceived spiritual well-being. Brusset and Brusset (2000) suggested other spiritual-related interventions such as yoga, meditation, T'ai Chi, etc. resulted in spiritual well-being. These were found to be examples of recreation/leisure that helped those searching for a more meaningful life. Heintzman (2010) found solitude leisure to offer peace, tranquility, chance for inner journey, and time for self-reflection. 
Spiritual-related interventions in recreation therapy. Heintzman (2002) termed Brusset and Brusset (2000)'s interventions as sacralization or resacrilization. Examples of sacralization are rhythmic breath work, creative visualizations, and imagery and awareness exercises (Heintzman, 2002) and meditation. Heintzman (2002, 2008) considered T'ai Chi to be a grounding leisure because it fosters a connection to the physical body and literally, to the ground. Gardening, jogging, and walking are also other examples of grounding spiritual interventions (Heintzman, 2002, 2008).

On the other hand, the researchers suggest leisure activities related to mass media, sports, socialization, and travel activities, tends to repress spirituality and spiritual wellbeing. Bellamy, et al. (2007), Heintzman (2002, 2010), and Stringer and McAvoy's (1992) studies did not substantiate the claim that socialization negatively affects spiritual well being. Furthermore, the travel activities did not agree with Goodnow and Rudell (2009) or Schmidt and Little's (2003) findings.

Goodnow and Rudell (2009) explored spiritual-motivated adventure travel. They found that the participants did indeed experience spirituality by renewing themselves through adventure travel. Other outcomes show the participants had a deeper sense of themselves, better connection with nature and the universe, and enhanced understanding that simplicity led to a happier life. Heintzman (2010) also agreed that leisure involving adventure is conducive to spiritual well-being. Schmidt and Little (2003) conducted an empirical study that questioned spiritual leisure experiences through a range of locations, contexts, and interpretations, but focused on identifying the common aspects that constituted spiritual experiences. They found four triggers conducive to spirituality as 
discussed earlier. Overall, travel was significant to one's spiritual well-being because of the aspects of reflection, connection and epiphanies, inspiration and self-discovery, and incorporating the mystical.

Another spiritual intervention was examined in Griffin and LeDuc's (2009) mixed method study. They found that adventure-based programs at summer camps had "activities (such as rigorous exercise, adventure, time alone for reflection) that have become a core curriculum of adventure education and were found crucial for spiritual growth" (p. 212). Results indicate that activities that contribute most to spiritual wellbeing are solitude, wilderness or peak experiences, and relationships with instructors and other participants.

Out of these activities, the researchers found that the individual/solo where participants are alone in wilderness for an extended time was the most effective with spiritual growth. The solo provides space and time to reflect which often involved pondering and sensing something greater than themselves, and improved awareness nature, others and themselves. This reiterated the domains of spiritual well-being from Gomez and Fisher and Heintzman's research.

Other recreation interventions/activities found to affect spirituality are challenge courses, rock climbing, backpacking, and whitewater rafting. Henderson, Oakleaf, and Bialescki (2009) conducted an empirical study and the spiritual outcomes of camps. They used the Spiritual Well-Being Scale pre and post camp. Interestingly, camps categorized, as "religious affiliated" had no significant changes on one's spiritual wellbeing as opposed to camps identified as "non-religious." The data also revealed camps 
that advertised as being spiritually focused was not a significant factor for clients to enroll. Overall, mixed results were found based on the comparisons between the interviews and the Spiritual Well-Being Scale scores.

Groff, et al. (2009) found that the combination of exercise and Recreation Therapy to be conducive to spiritual well-being for women recovering from breast cancer. The "Get REAL and Heel" breast cancer program used the Leisure and WellBeing Model, which provided clients an opportunity to strengthen mind and body connection. The program helped improve physiological, emotional, and cognitive functioning through interactive computer programming called biofeedback, which led to reduced stress levels and improved physiological homeostasis. Biofeedback creates a stabilized physiological state and heart rate, which creates a sense of inner harmony and increased awareness of self and others (Groff, et al., 2009).

By fostering spiritual development, the researchers introduced participants to skills and emotional capacity to engage and sustain one aspect of physical harmony called Heart Rate Coherence. Heintzman (2010) agreed with Groff, et al. (2009)'s results.

Overall, Groff, et al. (2009) found the "Get REAL and HEEL" breast cancer program also had spirituality-related outcomes such as finding meaning, life values, transcendence, and a sense of connection to others. Health care professionals increasingly support the belief that the process of "'meaning-making' and creating a sense of order and life purpose as one of the most critical factors influencing spiritual well-being and health" (Groff, et al., 2009, p. 342). 
Besides camps and exercise programs, boating has been found to be conducive to spiritual well-being. Parry (2009) studied women diagnosed with breast cancer through Dragon Boat Racing. Researchers reported three outcomes related to spirituality: (a) spiritual reflection and awakening, (b) spiritual connections with others and the universe, and (c) spiritual empowerment and association to survivorship (Parry, 2009). Dragon Boat Racing is a type of leisure that led to a deep commitment to something greater than themselves, decreased stress, and increased understanding of the importance of spirituality to their health (Parry, 2009) ultimately led them to achieve being a survivor of breast cancer. This points to a link between leisure, spirituality, and health (Heintzman \& Mannell, 2003).

Like Parry, Peace (2009) investigated the outcomes of canoeing and spirituality and reported improved sense of oneness, sense of one's place in the world, and connection. These traits reflect the domains of spiritual well-being mentioned earlier. Peace also found that the participants had enhanced connection with nature, the canoe, their spirit, and the Canadian culture. One interesting outcome found in Peace's (2009) study that was not found in others pertained to letting go of or modifying outdated habits. Peace (2009) explained:

Purpose of losing mental and physical baggage is not to lose it entirely and for eternity, but instead to re-evaluate, decrease, and modify it; to grow mentally, physically, and emotionally; and return to the world with new insight and perspective on life and society (p. 232).

This type of reflection and reevaluation helped participants to achieve a sense of stillness established from canoeing which enabled them to further connect and find their meaning and purpose in life. Peace mentioned, "The canoe is a watercraft pointed at each end, but 
there is a third thing that makes it a canoe... and nobody really knows what it is" (p. 236). Peace (2009) eluded that the third element to be spirituality.

Not all scholars agreed that leisure is always linked to spiritual experience. Some purport that spiritual well-being relies on the participant's intention in order for spiritual well-being to be experienced (Heintzman, 2002, 2010; Parry, 2009). Without that intention, the experience is simply an activity done for the sake of doing it, not for a deeper, meaningful purpose. "Spiritual rejuvenation is brought about only when an activity is congruent with the purposes or roles of a person" (Heintzman, 2010, p. 79). An individual cannot cause a spiritual experience to occur because it may also happen spontaneously, but if one has the intention to seek it, it is more likely to occur (Heintzman, 2002).

Heintzman (2002) found that spiritual experiences might only occur if the leisure experiences produce behavioral change or transformation in one's life. There must be some observable change the participant directly attributes to the spiritual experience. It is such a spiritual experience that Heintzman (2002) found produces greater locus of centricity, greater connectedness, and enhanced leisure attitude. This reflects outcomes found by previous researchers.

Heintzman (2009) conducted a meta-analysis to provide an integrated, critical synthesis of empirical studies related to spirituality and leisure that has been published in the last 18 years. One of the themes the researcher found was spiritual coping with stress

Heintzman and Mannell (2003) suggested that spiritual functions of leisure such as sacralization (leisure sensitizes one to the spiritual) and place processes (nature, sense of place, being away) might serve as coping strategies to ameliorate the negative influence of time pressure on spiritual well-being (p. 425). 
Leisure may indeed be used to cope with illness. The Restorative Environment Theory may also be a method of spiritual coping to stress.

Spiritual-related interventions in prisons. Joblin (2009) observed that, "In concentration camps, in prisons, even factories, colleges and well-meaning nursing homes, people who have little control experience lowered morale, more stress, and more health problems" (p. 114). In other words, individuals who have control over their lives have shown positive feelings of well-being. For individuals who have little control or little freedom to choose have shown very negative feelings, which lowers one's wellbeing. Having a sense of control seems to be very crucial to one's spiritual well-being.

Phillips (2001) studied male prisoners by teaching skills in self-awareness, emotional self-management, relaxation, and meditation. The researcher found that inmates upon entry to prison are faced with finding their identity and establishing their status all over again. This type of environment strongly shapes inmates to express their masculinity to others. Recouping manhood arises out of the environmental stress, loss, and deprivation. The harsher the environment, the more pronounced the behaviors. Furthermore, all possessions, relationships, environments and even human rights are taken away from them. One of the only things left to lose is their gender identity. This phenomenon was found to be ironic given that behaviors stemming from masculine posturing were often found to be a cause for misconduct in the first place.

Mela, et al., (2008) also worked with prisoners, but examined the Association of Spirituality and Religiosity's Spiritual Well-Being Scale among inmates in a multilevel 
forensic mental-health centre. Results showed that inmates who had access to spiritual personnel and/or spiritual resources were more likely to report having hope and higher spiritual well-being. Participants who had higher life satisfaction also had higher spiritual well-being. Participants who scored high on the existential scale were more likely to have a buffer from anxiety and depression, which led to higher life satisfaction. On the other hand, those who had poor coping skills were more likely to have lower spiritual well-being. Forensic psychiatric patients tend to score higher on religiosity and spirituality scales compared to the general and inpatient adult psychiatric populations. Finally, the researchers found that there may be an ethnically based difference among the existential and religious sub-scales.

Yoga and meditation in health care. Herriot, Schmidt-Wilk, and Heaton (2009) studied participants who practiced Transcendental Meditation (TM) technique. Transcendental Meditations is a simple, natural means for the mind to experience a quiet, still state of mind that has an alertness and clarity. The researchers found that those who engaged in TM were able to remain calmness under pressure. Participants achieved three dimensions of coping: inner stability, perspective, and renewal. Inner stability referred to having a strong foundation of internal happiness that was unaffected by eternal factors. Perspective is how a person perceived events and challenges that occur in life. Finally, renewal is the ability to release any tensions and overcoming stress. The outcomes also showed improved holistic functioning defined as an awareness of integrating internal and external dimensions of life into a greater wholeness. Finally, participants exhibited increased sense of connectedness and motivation. 
Szalavitz (2010) also found meditation to be a significant effect on participants' well-being. The researcher found that mindfulness meditation reduced psychological distress and increased longevity. Carlson and Larkin (2009) believed that breathing exercises also have positive outcomes of mindfulness and connection to everything. Focusing on the breath can help a person to move into the present moment and recognize a connection. Attention to one's breath can be helpful in promoting a more mindful way of living. Meditation helps one to transcend a sense of body-mind boundaries, as well as fears, in order to acquire deeply relaxing state experiences (Carlson \& Larkin, 2009, p. 384).

Mindfulness Meditation (MM) has helped with personal development, alertness, controlled breathing, and quiet attention that focuses on one's breath and/or a particular word or phrase (i.e., "mantra"). Szalavitz (2010) also found that meditation resulted with feelings of relief, peace, wholeness, healing, and awareness that were sometimes referred to as bliss or pure consciousness. $\mathrm{MM}$ was suggested to be a form of emotional-coping. Another form of meditation that was studied was Vipassana Meditation (VM), which has been said to be a similar form to MM. Carlson and Larkin, (2009) studied incarcerated people with substance abuse who were trained to use VM. The participants completed a 10-day intensive training where they were housed separately from each other and were accessed to any outside contact during this period. Three months after the participants' release from prison, they have significantly decreased the use of drugs and alcohol. There were higher levels of optimism, greater internal locus of control regarding 
alcohol, and decreased psychiatric symptoms. These outcomes suggested that VM was significant to one's spiritual well-being.

Mindfulness-Based Stress Reduction (MBSR) is a standardized meditation practice that integrated mindfulness mediation and modern clinical psychology. Chiesa and Serretti (2009) found that Mindfulness-Based Stress Reduction (MBSR) "teaches to observe situations and thoughts nonjudgmentally without reacting to them impulsively, helps people to develop a more reflexive awareness of inner and outer experiences, and could represent an efficacious tool for the reduction of stress" (p. 594). MBSR included techniques of body scan, sitting meditation, and Hatha yoga practice. There was a significant difference with participants' enhanced spirituality and reduced stress levels.

Vhora-Gupta, Russell and Lo (2007) argued that the adoption of Eastern practices such as meditation and yoga in the Western culture has increased as individuals have sought alternative to self-discovery and spirituality. The researchers found that meditation increases spirituality, health, and complimented therapeutic interventions. This study also deciphered that Western culture sought meditation with an intention of spiritual fulfillment, form of exercise, and/or complement to therapy. Eastern cultures practice meditation with an intention of seeking enlightenment.

Derezotes (2000) conceptually evaluated the effects of yoga and meditation on adolescent sexual offenders. Yoga significantly helped participants control physiological indicators of stress such as blood pressure, heart rate, respiratory operations, metabolic rate, brain waves, body temperature, and skin sweating. It was helpful for those who had medical problems such as cholesterol, diabetes, substance abuse, asthma, heart disease, 
headaches, cancer, and arthritis. Researchers concluded, "Yoga and meditation may help relieve symptoms of posttraumatic stress" (Derezotes, 2000, p. 102). None of the participants relapsed with sexual offenses during the time of the study and it assisted participants in their personal spiritual development. Outcomes show increased selfcontrol of their thoughts, feelings, and impulses as well as improved compassion for others and ability to explore deeper parts of one's mind. Some specific examples include having a sense of being treated with care, respect, and humanness from others that they did not feel before. Some also explained that their thoughts became places of safety and rest rather than a source of unwanted impulses.

Brown and Gerbarg (2005) conducted a conceptual meta-analysis study on prisoners and the Sudarshan Kriya Yoga program. They found that it significantly reduced violent behaviors and improved quality of life for prison staff and inmates. Sudarshan Kriya Yoga was found to be a low-risk adjunct treatment of stress, anxiety, PTSD, depression, stress-related medical illnesses, substance abuse, and for rehabilitation of criminal offenders. Yoga also enhanced well-being, mood, attention, mental focus, and stress tolerance.

Yoga and meditation in recreation therapy. Francis (1991) reviewed current research on meditation and deduced the specific aspects of meditation that contribute to spiritual well-being to be: focused attention although being still, non-analytical, and nonjudgmental. The researcher found that meditation helped reduce alcohol abuse and that it may be an effective treatment. 
Gim's (2009) research found that mindful meditation had positive outcomes on participants. The research indicated benefits to mindful meditation to be increased awareness of the self, mind, body, peace, oneness, harmony with mind and body, internal balance, well-being, and a positive sense of health. Heintzman (2008) suggested that yoga was identified as a spiritual coping activity that facilitated "concentration or focus of attention," which assisted in determining direction in life (Heintzman, 2008, p. 62). Spiritual interventions and recreation therapy in prisons. During the course of this review of literature, this researcher did not find and articles or studies that examined spiritually focused interventions in prison settings. This study was conducted to fill this gap. 


\section{Chapter Three}

\section{Research Methods}

The purpose of this research was to analyze a Recreation Therapy yoga meditation intervention called the Sanatana Yoga Prison Project (SYPP) at a California prison to determine whether the participants experienced outcomes of spiritual well-being as a result of this program. This investigation used a mixed-method approach that included a quantitative standardized instrument, the modified Spiritual Well-Being Scale (modified SWBS), a demographic data sheet, and a semi-structured interview (see Appendix A for the modified SWBS and see Appendix B for demographic data sheet). This chapter presents the research design, participants, instrument, procedures, and data analysis.

Research design. Spiritual well-being could be subjective; therefore, this study implemented a mixed-method design. The advantages of utilizing a quantitative method were that the results can be more objective, distinguished, and definite compared to the qualitative method (Stenius, Mkela, Miovsky \& Gabrhelik, 2008). The qualitative method's advantage was analyzing concepts that were not easily captured quantitatively, such as human behaviors, social processes, or matters (Stenius, Mkela, Miovsky \& Gabrhelik, 2008). A combination can help deepen the data analysis (Stenius, Mkela, Miovsky \& Gabrhelik, 2008) and the rich data may blend abstract concepts in the form of words to illustrate the discussion (Gratton \& Jones, 2004). The modified SWBS scores, the demographic data sheets, and the transcribed interviews were analyzed in this study. 
The SYPP is the treatment intervention, and served as the independent variable for the experiment group of this research. SYPP was a yoga meditation program that has been facilitated at a California state prison since June of 2010 . The facilitator was a Registered Yoga Teacher (RYT) as well as a Recreation Therapist working in the mental health department. The SYPP curriculum is structured around pranayama (breathing techniques), asana (physical postures), and dhyana (meditation). The meditation methodology incorporated the yogic chakra system and mindfulness-based strategies, but inmates who participated in the SYPP were encouraged to use any meditation method or form of prayer most comfortable to them. Classes may have also included selected readings and open discussions related to morality and spirituality. The SYPP took place in the prison's gymnasium at least once a week, for duration of up to two hours.

Before collecting data, this researcher took several actions to ensure validity. The student researcher completed a bracket interview to help clarify and obtain an objective, unbiased perspective, thus making the researcher more neutral to the topic and open to understanding the participants' point of view (Maxwell, 2005). According to Dale (2000), this helped bring any bias the student researcher may have had on a conscious level. A reflective/audit journal was also maintained throughout the research by the student researcher. This was highly recommended by Ortlipp (2008) because "critical self-reflection is a way of considering the ethics of the power-knowledge relationship with [the participants]" (p. 703). This allowed the student researcher to reveal any research details not typically seen in qualitative studies. This can prevent the same unnecessary process(es) in future research designs and procedures (Ortlipp, 2008). 
Finally, in order to strategize for research validity, the student researcher implemented a between-subjects design to have a better distinction and comparison of whether the inmates who have participated in the SYPP had experienced any outcomes of spiritual well-being.

A published survey called the Spiritual Well-being Scale (SWBS) was used in this study. The SWBS has shown to have strong validity and reliability in relation to measuring spiritual well-being through its subscale called Religious Well-Being, which measured a person's relationship with his/her religious beliefs (Bliss, 2009; Boivin, Kirby, Underwood, \& Silva, 1999; Ellison \& Paloutzian, 2009; Ellison \& Smith, 1991). It also had strong validity in measuring one's existential well-being as it has been able to measure one's sense of purpose in life and meaning (Bliss, 2009; Boivin, et al., 1999; Ellison \& Paloutzian, 2009; Ellison \& Smith, 1991).

Experiment group. The target population for the experiment group derived from the pool of participants currently or had engaged in a minimum of three or more of the SYPP interventions at the prison during the past three years between June 2010 and March 2013. The goal was to conduct about 10 to 15 interviews from the experimental group. The final total number of interviews was determined when the data information became redundant or saturated (Drayer, Shapiro, Dwyer, Morse, \& White, 2010; Butryn \& Chin, personal communication, September 20, 2010).

The procedures for implementation began when an inmate volunteered to be interviewed. The Recreation Therapist then provided an interview guide to the interviewees to allow them the time to gather their thoughts before the interview (Butryn 
\& Chan, personal communication, September 7, 2010). The interview guide consisted of 12 questions formulated by the student researcher and was based on the literature review in this document (see Appendix C). The Recreation Therapist scheduled the interview appointments ahead of time according to the interviewer and interviewee's availability. The Recreation Therapist collaborated with the prison guard(s) to determine the location of the interview. The interview was estimated to last between one to two hours with the caveat that it could last longer. Dale $(1996,2000)$ explained that the interview time is ultimately dependent on each participant's ability and willingness to share.

Control group. Participants in the control group were inmates who had never attended a SYPP session at the prison. Inmates willing to volunteer to be a part of the control group were asked to complete the modified SWBS and the demographic data sheet. Either the student researcher and/or the Recreation Therapist administered these documents.

Participants. This section presents a description of the study population and sample size. It discusses how the participants were recruited for both the control group and the experimental group.

Population and sample size. Participants were subjects who were at the time of data collection residing at a California state prison and who volunteered to participate in this research. This particular California prison was comprised exclusively of adult male inmates. The age of the participants ranged from 18 years old and up to 66 . The data were collected from inmates who were serving a prison term (called Main Line inmates). According to the latest public records at the time this study was conducted, California's 
total prison population dated in 2009 was estimated to be approximately 168,286 ("Average daily prison," 2010). The target sample size was projected to have a maximum sample size for each group to be 40 , which was based on the largest number of inmates allowed in one SYPP session. It was ideal to have a much larger sample size for this study, but due to restrictions and limitations with collecting data within the prison itself, it was out of the student researcher's control to be able to collect a larger target sample size to increase reliability (i.e., prison guards restricted inmates to be interviewed, conflict of inmates' work schedule, resistance from Watch Commander to interview inmate in person, etc.).

Recruitment of participants. The prison data collection took place from November 2012 through January 2013. The Recreation Therapist promoted the SYPP interventions by posting invitational flyers in all of the cells dorms throughout the prison facility (see Appendix D for SYPP invitational flyers). The Recreation Therapist walked throughout the prison dorms to recruit inmates for the experiment and control group by approaching mainline inmates and asking them if they wanted to participate. $\mathrm{He}$ explained the research purpose, protocols, and parameters. The Recreation Therapist also announced this research during the yoga class and asked the participants in the experiment group if they were interested in being interviewed about their experiences of the SYPP interventions.

Instrument. The Spiritual Well-Being Scale was chosen because it is a standardized published instrument that has been tested and demonstrated strong reliability and validity (Bliss, 2009; Boivin, et al., 1999; Ellison \& Paloutzian, 2009; Ellison \& 
Smith, 1991). Boivin, et al. (1999) stated that the SWBS is a holistic scale because it has been administered to a global psychological spectrum measures subjective quality of life.

This scale is a 20 -item, self-assessment tool using a 6-point Likert scale (ranging from "strongly agree" to "strongly disagree") containing two sub-scales: the Existential Well-Being (EWB) and the Religious Well-Being (RWB) scales. The two sub-scales address a sacred and secular approach to spirituality: (a) a relationship with the divine or what the person understands to be their spiritual being, or (b) a sense of satisfaction with life or one's life purpose (Paloutzian \& Ellison, 2009).

Each sub-scale has 10 items each. In order to address internal consistency and for control response bias, half of the items in each sub-scale are worded in reverse order so that there is a disagreement with an item that represents higher well-being (Bliss, 2009; Boivin, et al., 1999;Ellison \& Paloutzian, 2009). SWBS is a self-administered, pencil-and-paper survey that requires an average of 10-15 minutes to complete (Boivin, et al., 1999; Bliss, 2009; Ellison \& Paloutzian, 2009; Heintzman \& Mannell, 2003).

The student researcher made one change to the instrument thus creating a modified version of the SWBS: omitting the word God and replacing it with the word divine to acquire a more neutral language that appealed to a wider audience with different perspectives on spirituality. This version has been referred to as the modified SWBS in this research.

Procedures. Participation in the investigation was voluntary throughout the data collection period. The student researcher and/or the Recreation Therapist were the only persons who collected research data. The student researcher or the Recreation Therapist 
explained the purpose of the study to all potential participants by verbally stating that the participants' agreement to be a part of the research would contribute to the improvement of recreation therapy services by gaining detailed understanding of the SYPP outcomes.

This verbalization was repeated to all participants in writing through the San José State University (SJSU) Informed Consent Form, the CPHS Informed Consent form, one copy of the CPHS's Participant's Bill of Rights for Non-Medical Research in English and Spanish, and the prison's Inmate Declaration to News Media Contact form if the participant agreed to be interviewed for the experiment group (see Appendices E, F, G and $\mathrm{H}$ for the documents). If the inmate wished to participate in the project, the student researcher or the Recreation Therapist gave the participant two copies of all of the informed consent forms: one copy for the participants and the second for the student researcher's records. The student researcher and/or the Recreation Therapist then answered any questions by participants.

Institutional Review Board. The student researcher submitted all required documents to San José State University's Institutional Review Board, the State of California's Committee for the Protection of Human Subjects (CPHS) review board, and the prison's Institutional Review Board in order to receive approval to conduct this research. This research received approval and support from all identified authorities for the timeframe of August 2011 through November 2012. In particular, these requirements also included: the Warden's letter of support from terms 2011 and 2012, the prison's preliminary approval letter, the prison's IRB final approval, CPHS's letter of approval, and SJSU's IRB approval (see Appendices I, J, K, L, M, and N for all documents). Even 
though this research received IRB approval from various parties from 2011 through 2013 , research did not officially begin until all involved parties gave a final consent to begin conducting the study until November of 2012. This process alone took over a year to receive final consent. Because of this time lapse, the student researcher had to resubmit when an approval expired. San Jose State University's final approval was received on March 26, 2012 and was good until March 26, 2013. The Committee for the Protection of Human Subjects was received on October 5, 2012 and was approved up until August 30, 2013. Finally, the State of California - Department of Corrections and Rehabilitation was approved on November 14, 2012 up until August 30, 2013. In order to avoid resubmitting to extend an approval deadline, this study had up until March 26, 2013 to finish collecting data. Data collection occurred from January 2013 through March 2013.

Confidentiality. The student researcher intends to submit the results of this research for publication. Once published, the participants will be referred to by pseudonyms instead of their code names. In that case, the student researcher will choose the pseudonyms for all of the interviewed participants. The student researcher will be the only one who will know the identity of all participants. This will ensure maximum confidentiality of all the participants. The student researcher assigned pseudonyms EG29 to a participant named as experiment group 29. After publication, the student researcher will keep the audio recordings, transcripts, demographic data sheets, and the surveys in a locked cabinet that only the student researcher has access to.

The demographic data sheet asked participants to state their full name, age, race/ethnicity, level of education, and time served in prison. This has been supplemented 
with the modified SWBS. Participants chose a code name to ensure confidentiality. The code names have been written on their own interview transcripts, a demographic data sheet, and the modified SWBS. A separate list of the code names and the participants' real name have only been and will only be available to the student researcher. This code name list will be kept in the student researcher's home in a locked cabinet along with the participants' interview transcripts, demographic data sheets, and completed modified SWBS instruments for up to three years after publication.

The code names will be the only identification that will be available for inspection, if required. If this study is published, no identifiable or traceable characteristics, traits, or behaviors will be described that could possibly allow a reader to track the described traits back to an individual participant. If any material from this thesis is published, pseudonyms will be chosen by the student researcher and be used to identify the interviewees instead of the code names. Once published, the pseudonyms list will be destroyed thoroughly after three years by permanently deleting or shredding it along with the other research materials.

Risks. Participants may have experienced psychological or emotional discomfort as part of the risk of participating in this research. These risks may have risen from the interview questions, SWBS questions, and/or the demographic data sheet. Given the inmates' history of violence or impulsivity and their incarcerated context, questions on these instruments may have raised or triggered past painful memories, unresolved issues, or political/value system dissonance. 
In order to reduce these possible risks the participants in the experiment group were given the interview guide before the scheduled interview (see Appendix C) to prepare the participants psychologically and emotionally for the interview (Butryn \& Chin, personal communication, September 20, 2010). Further, the student researcher and/or the Recreation Therapist reassured the participants that the student researcher was the only person who was to have access to the participants' information. Inmates were appraised that if they chose not participate in the research at any time they would not be subjected to any adverse effects in their relations with San José State University or with the prison. Inmates were also reminded that in the event of emotional discomfort, qualified personnel within the facility are prepared to meet their needs at the time.

Data collection procedures. The first two interviews took place at a medical office in the clinic and the rest of the interviews took place in the Recreation Therapist's office. The participants were allowed to choose a code name to ensure confidentiality. The student researcher conducted all of the interviews. The student researcher asked every single interviewed participant the same set of questions from the interview guide in ascending order. The Recreation Therapist attended all of the interviews due to CPHS and prison research requirements to not have student researcher unattended with a participant for safety reasons.

The student researcher ensured triangulation of the data by ensuring there were multiple methods applied to the procedure to better understand the research phenomenon (Denzin \& Lincoln, 2006); therefore, once the interview transcripts were transcribed verbatim, participants were asked to validate their responses through member checking 
(Dale, 1996; Gratton \& Jones, 2004; Maxwell, 2005). The student researcher also had the Recreation Therapist review the contents and process of the data collection.

Finally, the student researcher audited a reflexive journal to ensure another method of increasing reliability and validity of the data collection. Any computerized documentations have been protected on the student researcher's personal laptop with a protected password and have never been unattended by the student researcher.

The qualitative data was collected only from the experiment group. The Recreation Therapist used convenience sampling to recruit participants. Dale (2000) recommended interviewing participants who can provide a variety of perspectives on the spiritual well-being experiences from participating in the SYPP. The student researcher asked the participants who were interviewed to share their experiences before and after the Recreation Therapy yoga interventions.

The Recreation Therapists and the student researcher had originally planned to use a systematic random sampling, but obstacles pertaining to prison procedures or limitations precluded this approach. For example, prison guards would restrict the Recreation Therapist/student researcher access to the participants despite this thesis having had received approval from the state of California's CPHS, San José State University and the Warden. The Recreation Therapist made multiple attempts to contact the potential participants to widen the participant pool but was unable to do so based on challenging politics within the prison itself.

Data analysis procedures. The quantitative data from the modified SWBS were computed using the original SWBS's published manual (Ellison \& Paloutzian, 2009). 
The RWB subscale inquiry was identified in the odd numbered question. The EWB subscale inquiry was identified in the even numbered questions. Adding these two subscales will result with the total SWB overall score. Table 1 summarizes how the modified SWB scores were interpreted according to their specific category. The demographic data sheets were analyzed using Microsoft Excel and SPSS 20. The modified SWBS scores were computed using SPSS 20 to complete a $t$-test and one-way ANOVA. According to Ellison and Paloutzian (2009), if the RWB score is between the scores of $21-49$, the participant is experiencing a moderate sense of religious wellbeing. If the participant scored between score of 50 through 60 , then he or she is experiencing a positive view of one's relationship with the divine. For the EWB subscale, if the participant scores between 21 through 49, it is suggested that this person is experiencing a moderate level of life purpose and For EWB scores between 50 though 60 , one is experiencing a high level of satisfaction in one's life and has a strong sense of one's purpose (Ellison \& Finally, those that score between 41 through 99, it is suggested that they have a sense of moderate SWB and those that have a score between 100 up to 120, it suggested by Ellison and Paloutzian (2009) that this person is experiencing a sense of high spiritual well-being. These statistics will be further discussed in the results section of chapter four. 
Table 1

Score Levels of the Modified SWBS

\begin{tabular}{lccc}
\hline Level & RWB & EWB & SWB \\
\hline Low & $10-20$ & $10-20$ & $20-40$ \\
Moderate & $21-49$ & $21-49$ & $41-99$ \\
High & $50-60$ & $50-60$ & $100-120$ \\
\hline
\end{tabular}

Note: Score level is interpreted according to the subscale definition. 
The qualitative data, the transcribed interviews, were analyzed using an existential-phenomenological approach in order to examine subjective experiences and phenomenon (Nagey Hesse-Biber, 2011; Dale, 1996, 2000). The student researcher conducted and transcribed all nine interviews word for word. All transcriptions were member checked by the participant himself. Two written responses to the interview guide questions were collected from two different participants from the experiment group. One written response was from a former prisoner who was released from the prison by the time date collection was initiated. Because the informed consent forms were not signed at the time of this written response and neither the student researcher nor the Recreation Therapist was able to help him complete these documents, his data were not computed with the rest of the transcribed interviews.

Therefore, this research included 10 interviews. The first two scheduled interviews were conducted in a prison medical office as it was not allowed at the time to have a Main Line inmate in the Reception Center, which is where the Recreation Therapist's office is located. The remaining six interviews were completed in the Recreation Therapist's office. The tenth interview is a written response from an inmate in a secluded wing. The materials were sent to this participant through a Watch Commander.

Once the interviews were transcribed verbatim, the next step entailed the following processes to develop themes: create meaning units, cluster initial thematic structures, develop the thematic structures (Dale, 1996), and consolidate emergent 
themes. Finally, the structure was then presented to the research group before reporting the data findings to the participants (Dale, 1996).

The student researcher and a thesis committee member reviewed all of the interview transcriptions and created meaning units throughout the entire qualitative data analysis process. Meaning units were phrases and quotes obtained from the interviewees. The meaning units were then analyzed again using an organized system for the data by categorizing them into similar subthemes. These subthemes were then grouped together based on shared meaning to represent general themes. These themes from the outcomes were identified based on interviewees experience from engaging in the yoga meditation intervention in the SYPP only. The themes then were organized again under two overarching categories. These overarching categories were formed based on physiological outcomes and psychospiritual/behavioral changes outcomes. The results of the interview categories, themes, and subthemes will be discussed in the results section of chapter four. 


\section{Chapter Four}

\section{Results and Discussion}

This chapter presents the study's findings and is organized into four sections. Section one is a description of the demographics of the sample that includes age, ethnicity, and the current amount of time they have been incarcerated at the time of the data collection. Section two concerns the quantitative results of the modified SWBS from both the experiment and control groups along with the demographic variables' effect on the modified SWBS scores. Section three presents the results of the qualitative data from transcribed interviews with the experiment group. Finally, section four is a discussion of the overall results from this research.

Demographics. This section presents the frequency distribution of the demographic information of the respondents from both the control and experiment groups. The demographic information obtained from the demographic data sheet had three variables: age, ethnicity, and total amount of time currently incarcerated. There were 31 participants in the control group and 31 participants in the experiment group. Table 2 summarizes the results. 
Table 2

Participants' Demographic Information

\begin{tabular}{|c|c|c|c|c|c|c|c|}
\hline \multirow[t]{2}{*}{ Variable } & \multirow[t]{2}{*}{ Items } & \multicolumn{2}{|c|}{ Control } & \multicolumn{2}{|c|}{ Experiment } & \multicolumn{2}{|r|}{ Overall } \\
\hline & & $n$ & $\%$ & $n$ & $\%$ & $n$ & $\%$ \\
\hline \multirow{7}{*}{ Age } & $18-24$ & 5 & $8.2 \%$ & 1 & $1.6 \%$ & 6 & $9.7 \%$ \\
\hline & $25-30$ & 2 & $3.2 \%$ & 4 & $6.5 \%$ & 6 & $9.7 \%$ \\
\hline & $31-40$ & 6 & $9.7 \%$ & 12 & $19.4 \%$ & 18 & $29.9 \%$ \\
\hline & $41-54$ & 9 & $14.5 \%$ & 10 & $16.1 \%$ & 19 & $30.6 \%$ \\
\hline & $55-64$ & 8 & $12.9 \%$ & 4 & $6.5 \%$ & 12 & $19.4 \%$ \\
\hline & 65 and older & 1 & $1.6 \%$ & 0 & $0.0 \%$ & 1 & $1.6 \%$ \\
\hline & Total & 31 & $50.0 \%$ & 31 & $50.0 \%$ & 62 & $100 \%$ \\
\hline \multirow{7}{*}{ Ethnicity } & Hispanic & 7 & $11.3 \%$ & 2 & $3.2 \%$ & 9 & $14.5 \%$ \\
\hline & White & 12 & $19.4 \%$ & 6 & $9.7 \%$ & 18 & $29.0 \%$ \\
\hline & Black & 10 & $16.1 \%$ & 17 & $27.4 \%$ & 27 & $43.5 \%$ \\
\hline & Native Indian & 1 & $1.6 \%$ & 0 & $0.0 \%$ & 1 & $1.6 \%$ \\
\hline & Other Asian & 0 & $0.0 \%$ & 1 & $1.6 \%$ & 1 & $1.6 \%$ \\
\hline & Other & 1 & $1.6 \%$ & 5 & $8.1 \%$ & 6 & $9.7 \%$ \\
\hline & Total & 31 & $50.0 \%$ & 31 & $50.0 \%$ & 62 & $100 \%$ \\
\hline \multirow{7}{*}{ Time } & 6 months -1 yr. & 5 & $8.1 \%$ & 1 & $1.6 \%$ & 6 & $9.7 \%$ \\
\hline & $1-5$ yrs. & 11 & $17.7 \%$ & 8 & $12.9 \%$ & 19 & $30.6 \%$ \\
\hline & $6-10 \mathrm{yrs}$ & 4 & $6.5 \%$ & 7 & $11.3 \%$ & 11 & $17.7 \%$ \\
\hline & $11-15$ yrs. & 0 & $0.0 \%$ & 4 & $6.5 \%$ & 4 & $6.5 \%$ \\
\hline & 16 - lifetime & 8 & $12.9 \%$ & 5 & $8.1 \%$ & 13 & $21.0 \%$ \\
\hline & Other & 3 & $4.8 \%$ & 5 & $9.7 \%$ & 9 & $14.5 \%$ \\
\hline & Total & 31 & $50.0 \%$ & 31 & $50.0 \%$ & 62 & $100 \%$ \\
\hline
\end{tabular}


Analysis of the SWBS scores. This section presents the comparison between the control group and the experiment group's modified SBWS scores. This will reveal whether the experiment group showed outcomes of spiritual well-being by engaging in meditation and yoga from the SYPP or not compared to the control group.

A $t$-test with a two-tail analysis was utilized to analyze the modified SWBS scores. The observation significance level was .05 . The demographics were then statistically tested through one-way ANOVA to better understand if any of the demographic variables significantly affected the modified SWBS scores or not for either group. The $\mathrm{p}$ value was set alpha at .05 .

SWBS scores. This section presents the SWBS scores for both the experiment group and the control group as related to spiritual well-being. The results are summarized in Table 3. The outcomes of the $t$-test suggest that there was a statistical significance in the Religious Well-Being (RWB) scores $(t=3.15, \mathrm{p}=.003)$, the Existential Well-Being (EWB) scores $(t=3.70, \mathrm{p}=<0.001)$, and the total Spiritual WellBeing (SWB) score $(t=4.03, \mathrm{p}=<.001)$.

All three scores show statistically significant difference between the control group and the experiment group. Furthermore, analyzing each mean score of the experimental group, all three scores suggested that this group may have possibly experienced high spiritual well-being as a result of engaging in the $\mathrm{SYPP}(\mathrm{RWB}=50.9, \mathrm{EWB}=0.7, \mathrm{SWB}$ $=101.2)$ compared to the control group's mean scores. The control group's scores suggested that this group experienced moderate spiritual well-being, which may be 
possibly be due to them having had never engaged in the SYPP $(\mathrm{RWB}=42.9, \mathrm{EWB}=$ $42.8, \mathrm{SWB}=85.2$ ).

Effects of demographics on SWBS scores. One-way ANOVA was used to examine whether any of the demographic variables had any significant effect on spiritual well-being. Table 4 summarizes the results for the effects of age on the RWB, EWB, and SWB scores. Table 5 summarizes the results for the effects and the RWB, EWB, and SWB scores and time incarcerated. Ethnicity was an unbalanced sample size; therefore, the student researcher was unable to compute statistics. 
Table 3

Comparisons of the Modified SWBS Scores between Experiment Group and Control

Group

\begin{tabular}{lccccc}
\hline Variable & Control & & Experimental & Significance \\
& Mean & SD & Mean & SD & $t$ \\
& & & & & $3.15^{*}$ \\
& & & & & \\
RWB & 42.9 & 10.2 & 50.9 & 9.9 & $3.70^{*}$ \\
EWB & 42.8 & 8.9 & 50.7 & 7.7 & $4.03^{*}$ \\
SWB & 85.2 & 15.4 & 101.2 & 15.8 & \\
\hline
\end{tabular}

$* p<.05$. 


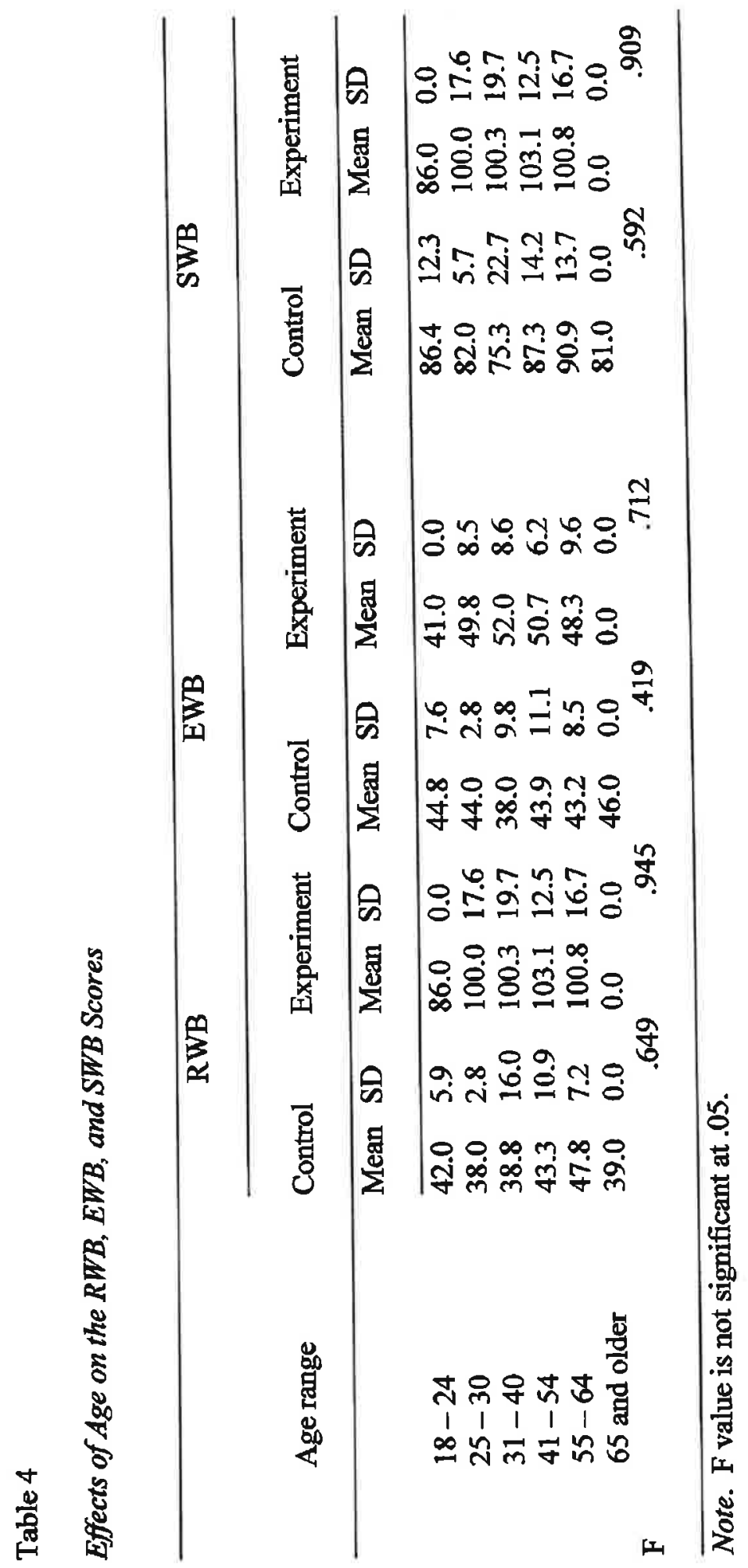




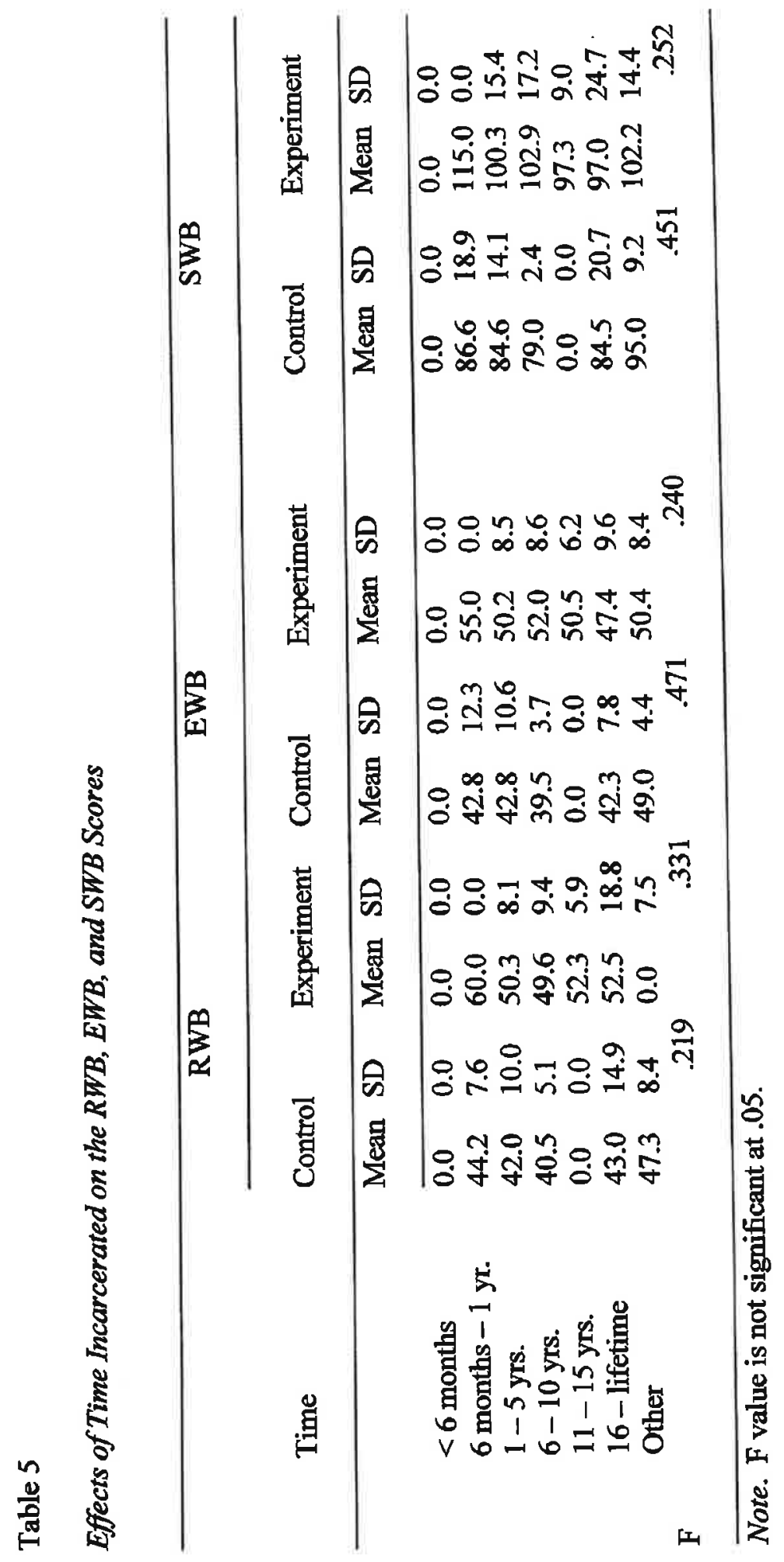


Analysis of interviews from experiment group. There are two overarching categories from the interviewed participants: (a) concrete outcomes, and (b) psychospiritual development. Table 6 summarizes these outcomes. The first overarching category, concrete outcomes, represented themes that were immediate conscious-level results from engaging in the SYPP's interventions. The second overarching category, psychospiritual development, referred to a deeper level of consciousness that allowed the SYPP participants to begin to change their way of thinking, their way of behaving, and their overall way of living life.

Concrete outcomes. Concrete outcomes referred to the following four themes: (a) physical benefits, (b) escape, (c) quieting the mind, and (d) reflection. The following is a review of each theme.

Physical benefits. Participants in the experiment group all talked about how participation in the SYPP intervention helped them to feel an immediate sensation of relaxation and calmness. Relaxation is described by majority of the participants as releasing the physical tensions in the body and mind so and to begin to feel more at ease. For example, EG 25 said, "You can't help, but when you are doing and holding the poses, is just to really let yourself relax cause if you don't, then you stay tensed up. I learned that early on so about midway through, I kinda, you know, let go of that." He added, "The yoga was starting to help and as I was going through the exercises, I didn't realize how tight I was. You know. I was really wind up tighter than a clock! So I started to feel my body." 
Table 6

Summary of Experiment Group's Interview Outcomes

Overarching Categories

Concrete Outcomes Psychospiritual Outcomes

Physical benefits Epiphany

Themes Escape Connection to self and other

Quieting the mind Psychological \& behavioral change

Reflection Coping skills

Another participant, EG 31 described this phenomenon, "Well...my body is feeling at ease. Totally relaxed." This type of relaxation produces a source of stress relief EG22 described, "If I feel a little 'stress out,' I do yoga. Minutes later I feel rejuvenated with a sense of answers to my problems because I know I have a place where I can go to find the answers I need." EG24 complimented this thought, "When I'm doing yoga and mediation and I cannot explain it in other words, but it's the spiritual strength, you know. Cause I know I'm not doing weights or I'm pushing ...I'm not stressing or anything. It's a feeling within my body, and I believes it's the spirit, you know I get that...I get that from meditation and yoga."

Calmness is another aspect of physical benefit. This is defined as a feeling at ease throughout the mind, body, and spirit. When one is calm, it is less possible to act on 
impulses like the past. Situations that triggered negative emotional outbursts in the past are no longer compelling. For example, EG23 reported, "It's helping you calm your anger...calm that emotion that you might be feeling at the time and use it in a constructive manner where you're doing some stretches or breathing techniques or meditating."

The breathing exercises and the meditation has induce more calming effects as been said by majority of the participants. This sense of calmness also seems to contribute to a decrease in chasing id level desires in order to experience higher consciousness. EG31 said this best when he explained, "Because [one is] not preoccupied with satiating [one's] calling desires." He explains that "... when these things are put in check, it calms the heart to a point, to a degree where it's just enveloped with peace" (EG31).

Escape. The second theme of physical benefits is that meditation and yoga, like most forms of leisure or recreation, provide escape from the mundane and even suffering. Mediation and yoga allow the participants to be able to remove themselves mentally from undesirable reality of prison. The constant reminders of their crime take a toll. A few of the participants shared how SYPP provides an escape from this heaviness. This heaviness could be negative weight from being around other inmates' animosity or having a heavy heart from feeling depressed about being away from their loved ones. So engaging in yoga seems to provide an opportunity to "feel like myself" again. EG30 added that he had "sense of relief from [prison]. It helps me to get away from problems that go on in here... and being away from my loved ones. Being around people you don't know, that don't understand you, and you don't get along with." 
Majority of the interviewed participants acknowledged that they were physically confined in the prison environment, but that they were still free in other aspects. For example, "The surroundings, the physical surroundings are really not what's important. The things that we can see. The thing that we generally perceive with our senses...it's not what's important because they're not real. And so, I think within that yoga, this constant yoga. This is something that is understood. There's a difference between the material and the truth. And the material changes" (EG27). The material meaning things that are perceived by the human eye. In addition, things that are perceived are not considered important because it is always changing. What never changes is truth and truth is either the divine or one's spirituality. Another participant mentioned about getting his freedom from prison.

Quieting the mind. Another concrete outcome from the SYPP was quieting the mind. This is described as being able to listen to their body when they would ignore it before when they weren't participating in the SYPP. For example, EG 23 said, "Thoughts come and go. You start getting deeper into your meditation. Your body starts to feel relax. Your breathing starts calming. You start to be more aware of your body." The body is constantly communicating with one about things it need such as hydration or healing an injury that one would have ignored before. One participant said that now, he could be more in-tuned with his body, that he was not clear-minded and had not learned to listen to his physical being ever before.

Quieting the mind seems to allow inmates to self-reflect. One participant described, " 
Sometimes we do need to stop and be still. Just let it go...take some time for yourself. See what you have been missing. Open up... your mind eye! Open up your heart. See what kind of energy... what kind of feelings you can [discover]...you'll be surprised! (EG23).

Quieting the mind tends to bring about new opportunities to sit and to be still. EG31 said, "I think that much growth can be obtained from sitting still. Often times, when we are moving about, and sitting still is not really an option for many people. They rather be distracted from a host of things instead of sitting still."

The participants demonstrate how yoga and meditation aide to calm constant running thoughts and to just be. When one quiets the mind, one has more clarity to process life circumstances, feelings, and thoughts.

Participants discussed the challenges of quieting the mind. EG23 explained,

Before [SYPP], meditation was hard for me cause you really have to sit still, control your breathing, and sit quietly in your thoughts. Like, 'Okay, what did I do today? Oh yeah, I have to do this. Oh, tomorrow I have to go pick up the groceries. I have to go shopping. I have to go get this and that.' You hold on to that. You get so attached to that. You don't let it go, but you learn to let them go.

If a participant did have the experience of quieting the mind, it looked something like EG23's sharing "that moment of just being still. [When I have] a hard time staying still in [prison]. Just quiet, peace, and use the white noise around you...the fan going on or just the band playing. Use that in your mediation to go with it. Let your thought go and just...it helps you. It calms you down."

Reflection. The majority of the participants had an opportunity to reflect on themselves during SYPP. Reflection, according to the interviewed participants, meant engaging in introspection and looking within oneself to finding the meaning and 
understanding of their life. EG25 said that he engaged in reflection for clarity when he wasn't able to do so being around the chaos of prison life. He shared,

In order to escape from [the violence in prison], sometimes it's the sanctuary of your own home is your cell. So, at the end of the day, I would sit and do some of the meditative practices and the breathing... and it started to change my outlook. I started getting into myself. I started doing some introspection on my outlook, on my change. Cause I knew that if I continue to live the life I was living, okay? I knew I would never get out of prison... so I knew I had to find a new way of life. And that literally started to change. Started to have a changed me.

Sitting and being still seemed to lead the participants into a different experience of self-reflection: inner listening. This meant hearing, not only with their ears, but also with the mind's eye or perhaps, the spirit. EG23 shared, "

Maybe things that you have been putting off...now you're able to hear, really hear...not with your ears, but with your spirit-being. You hold on to that thought you can't get into a deeper meditation because you tend to just constantly [think], your mind keeps going. [I say to myself,] come back and continue to doing it...breathing with it. It surprises you, you know. It helps you a lot!

Many participants talked about how they started to reflect on the quality of their day. For example, EG25 reported that he "at the end of the day before I got to sleep, I sit up in my rack where it's nice and quiet and I'll literally go through the day and see what I did right, who I interacted with or how I could done something better." Some shared how they would go out of their way the following day to ensure that mistakes were corrected and that relations were on good terms.

As EG31 explained, meditation helps to provide a more realistic perspective. He reflected, "I hate to look at it closely at times, it's a reality check at times 'cause sometimes you think you are at a place we like to refer to in Islam as a station." $\mathrm{He}$ 
admitted that because of the reflection that he was not as advanced as he was hoping to be and the challenge that comes with being "forced to accept that reality that you're not." Another outcome of reflection is having remorse regarding their crime and the desire for restitution. EG27 confessed,

So there were these moments when I felt like a fraud. But, you know, like most human beings, I had a wonderful capacity to rationalize and to delude myself. And so, I did that. Most of it. I think most of my life outside of my confinement. And once I was in prison I was forced to, at least in my mind; to take stock of [who I am] and to be honest with [myself] first." He went on to say, "I've been fortunate enough to come to terms with [my wrongdoings].

There are participants who shared that engaging in reflection also allowed them to try to change negative traits and to improve themselves. EG25 said, "Sometimes I catch myself resorting back to the old ways. The way of thinking. I had to stop and really remind myself where I'm at, 'Whom I'm talking to?' 'Where I am today?' Where as before yoga, I didn't take those things into consideration."

Psychospiritual Development. From the data emerged a second category of themes that coagulated around the overarching pattern of psychological and spiritual development. Here the inmates exhibited and discussed the ways in which they experienced behavioral change and shifts in view of self, other and the divine as a result of participating in SYPP. This category contains four salient themes: experiencing epiphany, increased connection, psychological and behavioral development, and coping skills.

Epiphany. The first theme pertains to verbalizations where the participant had a moment of clarity, insight, or awakening because of their participation in SYPP. Many also said that things began to make more sense to them compared to before when 
artificial things were more important. EG25 talked about a moment of insight about his life, "You made the decision to look at your life and...make changes. That's what that had helped me to do in the SYPP. I never took heed or I never understood because I didn't take the time to apply it to my own life... once I did, I made changes. I started making the change because I was like, 'Oh. Okay. I get it."

Many had a better understanding of what was more important in life compared to what they had thought before engaging in the meditation and yoga. EG23 gained a new outlook, "...Every day is a new beginning, a new journey. You experience different things each in every day in which you contribute to your life's journey so every day for me is meaningful as far as life.

Before SYPP, many inmates only exposure to spirituality was through organized religion. Another type of epiphany related to spirituality was having their religious faith to complement the SYPP interventions. EG31 explained, "I think that Islam complements the [SYPP] exercises that I've been engaging in over the years regarding spiritual purification...As I said earlier, [SYPP] complements the things that I do to further my spiritual well-being and perhaps the most important thing it does for me is that it allows for me to sit and reflect."

Another participant, EG27 adds, "I have found yoga to be a benefit as opposed to being in opposition to Islam...this is somewhat of a unique position amongst many Muslims who maybe don't understand yoga. But my understanding of it and my practice of it and with what I have learned from the Recreation Therapist and his program, I have found it to be a benefit in other aspects of my spiritual life....Muslim that is." 
SYPP seems to also have provoked a new understanding of spirituality beyond its potential symbiosis with organized religion. For example, EG25 shared, "Initially, I really wasn't spiritual but the more I got into the yoga and the more I read the different types of yoga and some other literature I was seeking, the more it introduced the Buddhist way of life."

This inmate's new awareness of the divine seems to enliven and excite him to learn "It is more of a way of life. I was able to accept that because it didn't conflict with anything."

EG25 explained how he became more aware of who he is and allowing himself to human. He discovered through SYPP that he began to,

Being more aware [of] my feelings towards people and my own feelings! I've gotten so numb over the years in prison. Like the death of my mother, my grandmother, my brother, my sister, my uncle. I knew there was nothing I can do outside of these walls, so there was no reason for me in here to get all choked up and boo hoo hoo cause tomorrow, I'll wake up to the same place. I literally had formed a callus over my heart, my feelings, which is the worst thing that I could have done to myself over the pass [years.] Because now, I'm expected to feel [because of the yoga and meditation.] And sometimes, that's hard because it comes out too, too, too quick. My emotions come out too easy, but then again, that's a good thing because it shows I'm human and who I am.

Finally, the majority of the interviewed participants also explained that prior to

SYPP they were taking daily experiences for granted and were not accustomed to appreciating 'the small things.' that they have taken for granted. For example, EG24 divulged, "Well [SYPP] changed my way of thinking and the way I feel about people. It taught me to come from the heart instead of from my head..."

Connection with self and other. It is easy if not imperative for people who are incarcerated to learn to isolate. Isolative behaviors might have been the norm before incarceration and after release from prison; individuals are again at risk of isolative 
behaviors. Although this helps inmates to survive, perpetuation of isolative behaviors during incarceration only leaves the individual at risk of continuing these maladaptive behaviors after being released from prison. Learning to connect with self and others is a sign of development for inmates who have learned to survive and to isolate.

One theme demonstrated through the data was an increase in connection with oneself and with others. An example of having a connection to oneself through SYPP is having a better sense of who they are. EG27 explains that everyone's physical flesh is not what makes a person a human being. It is the soul underneath the 'clay' that is what's significant. He says, "You see what you see is my physical appearance and I see is what is yours. Yet, what you see of me is not who I am. This guy who is over here listening. What I see in my peripheral, that's not him. And what I see of you is not you." As for connections with others, this is also described as something that is not seen with the human eye, but what is felt in one's spirit. "EG23 believed that "...[there are] some people you feel comfortable with. Like yoga. When you're stretching and doing the yoga exercises, you flow like the Recreation Therapist directs you." He went on to clarify that the pivotal catalyst was his relationship and being opening himself spiritually with the Recreation Therapist, "But it's a connection with him because you're going through the yoga, the breathing and mediation. So on a spiritual level, [Munshi and I] connected as one. So it just flows." Another inmate shared that connections with others are inevitable because EG27 added, "There's no way in the world, in my opinion, that an individual can say that they are striving for spiritual perfection or to realize spirituality 
and not be concerned about their neighbors or their fellow human beings. It's impossible."

Psychological and behavioral change. The third theme of the psychospiritual change is evidence of psychological and behavioral development. The results indicated that the participants began to demonstrate mature relational and behavioral skills as opposed to acting out impulsively and irrationally as in the past. EG25 said that he has changed his behaviors and thinking because he now is consciously aware of when someone is trying to evoke him by pushing his buttons, but...

Instead of butting heads with certain people, I was no longer getting part of any of it. I would let them do the venting. It was mainly that guy's drama. It's not mine. So, I started to take on those different ways of thinking. Different way of approaching people.

Before being a part of the SYPP, many were not able to consider other people's feelings and well-being. Many were immature in their selfish ways. Before being involved in SYPP the inmates revealed that they were selfish and didn't care about how they treated others. After SYPP, this perspective and behavior has morphed into a mature psychospiritual development. One inmate explained, "Everyday I want to teach somebody something in my actions and what I do and I actually learn from you. you don't wanna disrespect yourself cause that's how somebody would treat you."

Many have also mentioned that they feel humble and selfless as opposed to being selfish and unaware of one's surroundings before the SYPP. Many are now acting out of kindness without expecting anything in return. Many begin to notice reciprocity to occur. The more acts of kindness they did, the more they saw good things changes in their life in return. For example, “... with all of the good I've been doing. I think good comes back 
at me. And so the whole karma thing. And before, I was just...the more I struggle, the more I fought life" (EG25).

Coping skills. The inherent nature of SYPP activities provide concrete and immediately usable coping skills that can be applied to daily life. These skills can stave impulsiveness and cognitive distortions that lead to anger towards life situations.

EG31 explained how he operates in his daily life "on a spiritual level....just like water off a duck's back." He explains how when previously inflammatory incidences occur, "You don't let it affect you no more. You can carry yourself above the spiritual level and being in yoga has helped strengthened that." Situations that usually trigger negative emotions in him were now no longer eliciting impulsive reactions; as a result, his spiritual strength allowed him to understand that negative situations are not worth fretting over because it is not important in life. He learned to cope by understanding it is these negative situations are minor compared to what's more important in life- - one's spiritual well-being. What is more important is maintaining and building his spiritual strength to fight off these kinds of life situations. SYPP has helped him to do that. EG25 explained how he can now divert himself from getting into trouble after learning through the SYPP that a person cannot let another's negative energy or thoughts affect them. He had read a bible passage about how "... being the ruler of your own kingdom or your own temple... and it's true! I mean, I'm the landlord. So anything that goes on in my mind, I let people rent space in my head... allowing negativity to my head...or the devil to speak or evil thoughts." 
When others are trying to divert another person from his/her progress, the participants believed through engaging in the SYPP interventions that they don't allow others to bring them down. They remind themselves to continue with where their progress is at because "[the Recreation Therapist's] spirituality [and SYPP] has helped me to keep humble. Stay on the path. Don't let those around me bring me down" (EG23).

Summary. The total sample was 62 participants with 31 in the control group and 31 in the experiment group. The demographic of the participants in the control group was predominantly White or Black descent, incarcerated in prison between one to five years, and had an average age of 41 to 54 or 55 to 64 years of age. The average profile for the experiment group was of Black descent, who had been incarcerated for one to five years or five to 10 years and had an average of 31 to 40 or 41 to 54 .

All three scales' scores (RWB, EWB and SWB scores) from the modified SWBS suggested statistical significant difference between the control group and the experiment group's level of spiritual well-being possibly from engaging in the SYPP. . Furthermore, analysis of each mean score of the experiment group revealed that this group may have experienced high spiritual well-being as a possible result of engaging in the SYPP. The control group's scores suggested that this group experienced moderate spiritual wellbeing, which may be due to not being in the SYPP ever.

Finally, the qualitative results suggested outcomes of two overarching categories: concrete outcomes and psychospiritual development. Each category had four themes that demonstrated the outcomes of the SYPP engagement. The participants who were 
interviewed suggested that they experienced the following outcomes, which are categorized under concrete outcomes: (a) physical benefits of relaxation and calmness, (b) sense of escape from reality and prison life, (c) quieting of the mind by being in-tuned with one's spirit, and (d) reflection on one's past, present moment, and future. The second overarching category, psychospiritual development, had the following four themes from the SYPP interventions: (a) epiphany, (b) connections with self, others and the divine, (c) psychological and behavioral development, and (d) coping skills.

Discussion. The quantitative results revealed that there was a statistical significance between the control group's levels of spiritual well-being compared to the experiment group. It showed that the overall experiment group had high spiritual wellbeing compared to the control group resulting with moderate level of spiritual well-being.

The two overarching categories from the qualitative measures, concrete outcomes and psychospiritual development, were self-proclaimed outcomes that inmates experienced in the yoga meditation intervention from the SYPP. The themes that were extracted from these categories revealed that SYPP allowed the inmates to have a more meaningful epiphany. Initially, the physical benefits of relaxation and calmness helped their physiology by reducing their blood pressure, decreasing the feeling of being highstrung, and/or minimizing racing thoughts. The sense of escape from prison life and their reality through the SYPP gave them a sense of freedom. Even though they were still physically confined, the yoga meditation intervention made them feel emotionally, mentally, and spiritually free. It gave them an outlet to reflect on themselves, past behaviors, and thought processes. 
As they continued with the SYPP, they were able to quiet their minds from the busyness of life. They became more in-tuned to listening to their body with their soul, not literally with their ears. They were able to let go of their thoughts and be in the space and time of the moment. This led to reflection and introspection. When doing so, they had clearer clarification regarding what was more meaningful in life as opposed to what they had thought was important before. Their new learned coping skills such as not internalizing other people's negative energy or not acting on their impulses were now revealing the new changes within themselves. They started to have more control over their anger by putting their energy into something more positive, such as engaging in their favorite leisure. One inmate liked to play the guitar, and another enjoyed working on his next woodwork project instead of looking for another fight to start with others like he did before. They began to surround themselves with people they would have never thought of associating themselves with. For example, some inmates would be attending the Muslim services or having intellectual conversations with the prison staff members and peers.

Majority of the inmates had shared their history of abusing drugs and alcohol as a coping method. Not only did these substances influence deviant behaviors, it also deprived them of being able to trust their intuition. Many inmates used drugs to soothe themselves, but were now admitting that these behaviors were counterproductive and that was no real reward as a result.

Once they started getting deeper into the SYPP process, their life started to change for the better. Moreover, this meaningful epiphany derived healing. Healing is in 
regards to feeling remorse, forgiveness, and letting go of the past in order to change their way of thinking, acting, and living their life.

To be able to make up for their wrongdoings, many of the inmates decided to give back to the community by acknowledging their mistakes. Some were involved with giving back to the community by counseling at-risk youth to prevent them from making the same mistakes the inmates had made, which landed them in prison. The inmates were also more inclined to want to conduct themselves in a more honest manner. For example, they wanted to make a living without involving "dirty drug money."

Another example was being honest with oneself and allowing themselves to feel their own emotions, process them, and then cope when appropriate, but this time in a healthy manner. This allowed them to be able to move forward with their life. The ability to move forward that grew into a developed maturity. A maturity that the inmates were now taking responsibility for their own actions and giving back to others to make up for the wrongdoings they have done in the past.

These themes suggest that the yoga meditation intervention from the SYPP might be a platform for the inmates to heal and change their behaviors. Many inmates shared that their wish was to be set free from prison and transition back into society. In order to do so, they must demonstrate to the state of California's Board of Parolee Hearings committee members that they deserve to be released from prison because they have made positive changes in their lives. These changes for the better may be contributed through the SYPP increasing and improving the inmates' spiritual well-being. 


\section{Chapter Five}

\section{Conclusion and Recommendations}

The purpose of this research was to analyze a Recreation Therapy yoga meditation intervention called the Sanatana Yoga Prison Project (SYPP) at a California prison to determine whether the participants experienced outcomes of spiritual wellbeing, which may or may not have been due to participating in three interventions: (a) pranayama (breathing exercises), (b) chakra meditation, and (c) yoga.

Among 62 respondents, 31 participants were recruited for the control group and 31 participants for the experiment group. Both groups received a demographic data sheet, the modified SWBS, and a signed copy of each of the informed consent forms from San José State University and the state of California's Committee of the Protection of Human Subjects. The modified SWBS had two subscales that measured the RWB and the EWB. For the data analysis, frequency distribution, $t$-test, and one-way ANOVA test was used to analyze whether or not either the control group and/or the experiment group experienced spiritual well-being from engaging in the SYPP. The RWB, EWB, and SWB scores were computed using the original SWBS's scoring manual. Of the total of 31 experiment participants, 9 participants were interviewed in-person by the student researcher and one participant submitted a written response to the preset interview questions about their experiences from the SYPP. There were 10 interviewed participants total. Existential-phenomenological approach was used to analyze the transcribed interviews. 
Based on the quantitative results, majority of the participants in the control group were either White or Black descent, had been incarcerated between one to five years, and had an average age between 41 to 54 or 55 to 64 years of age. In comparison, the average profile for the experiment group was mostly of Black descent, incarcerated between one to five years or five to 10 years and was in between the ages of 31 to 40 or 41 to 54 years of age.

All three scales' scores (RWB, EWB and SWB scores) suggested there was a statistical significant difference between the control group and the experiment group's level of spiritual well-being that may be due to engaging in the SYPP. Furthermore, analyzing each mean score of the experiment group, all three scores suggested that they may have experienced high spiritual well-being possibly due to the SYPP. All three scores from the control group suggested that they may have experienced moderate spiritual well-being, which may be possibly due to having had never engaged in the SYPP.

The qualitative results had two overarching categories: (a) concrete outcomes and (b) psychospiritual development. Each category had themes that further explained the outcomes from SYPP participation. The participants who were interviewed shared that they had experienced the following outcomes from the first overarching category, concrete outcomes: physical benefits, escape, quieting the mind, and reflection. The second overarching category, psychospiritual development, had the following themes: epiphany, increased connections, psychological and behavioral development, and coping skills. 
This final chapter is composed of three sections. Section one is the conclusion of this study. Section two discusses the limitations of this study. Finally, section three presents the recommendations.

Conclusion. The student researcher was interested in the treatment intervention of yoga meditation on spiritual well-being. The research question was to analyze whether there were any outcomes of spiritual well-being from engaging in the SYPP. Both the quantitative and qualitative results suggested that the inmates who have participated in the SYPP may have experienced spiritual well-being possibly due to the Recreation Therapy intervention. The statistics suggested that there is an outcome experience of spiritual well-being, and those that volunteered to be interviewed have all suggested that the SYPP was responsible for them to be able to have spiritual well-being; therefore, there is a possibility that the SYPP is conducive to spiritual well-being and that the inmates may have experienced outcomes of it. However, due to limitations that were outside of the student researcher's control, this conclusion can only suggest that there may be an outcome of spiritual well-being due to the SYPP. More research is required to obtain a stronger understanding of this.

Limitations. The research design had a total sample of 62 participants. The inability to collect a large sample size was due to barriers that were beyond the student researcher's control. Student researcher was not able to neither collect a very large sample size nor administer with a random sampling. The total number of participants interviewed was based on how many inmates were willing to volunteer to share their SYPP experiences. One of the 10 interviews transcribed was a written response to the 
interview guide questions. This particular inmate was restricted access to outside of the inmate's dorm as he was located on a wing that was on lock-down due to violating a prison rule.

The student researcher was not able to collect data before and after the SYPP interventions by administering a pre- and post-survey. The student researcher also did not use qualitative data analysis software to transcribe and interpret the interviews. Instead of using random sampling, convenience sampling was implemented instead.

Many changes took place in the prison during data collection for this study. The entire California prison system was restructuring in compliance to a criminal justice realignment that was related to an assembly bill called AB109. The Warden had changed twice since this research has been initiated in 2010 . The prison has changed from a primarily Reception Center prison to a mainline prison primarily. At a Reception Center prison, inmates had very few services although they were classified and held before serving out their term at a mainline prison.

In addition, every few years, the prison employees bid for a change in their current work status and/or schedule within each prison. This occurred right before the data collection officially began in January 2013; therefore, the new prison guards who were assigned to monitor the gym area where the interventions took place have made it more difficult for the SYPP facilitations to take place than before. They were also restricting inmates to be out-counted from their dorm so that they could migrate to the Recreation Therapist office located in the Mental Health Department to be interviewed. 
This would also set time limitations of when the interview could be conducted throughout the day.

Another limitation to this study was the extensive timeline for multiple IRB approvals to be obtained. The student researcher had to submit multiple documents to San José State University's IRB as well as the prison's research program committee, and the state of California's Committee of the Protection of Human Subjects' committee. This was initiated during the fall of 2011.

The prison's research program committee initially granted preliminary approval beginning in February 2012. San José State University's IRB then gave final approval in March 2012; however, once the final approval was granted by the state of California's Committee of the Protection of Human Subjects' committee in October 2012, final approval from the prison's research committee was finally granted by November 2012 . Data collection did not officially begin until January 2013 due to research preparations. Because of the extensive timeline on retrieving approval from all three parties, this study was then limited to having a strong group control. It would have been ideal to have a longer period to be able to collect data before and after the SYPP interventions.

Finally, the student researcher based the interview guide questions from the literature review on leisure and spiritual well-being created. The questions did not focus much more on asking the participants about their experiences from the SYPP except for the last two questions on the interview guide.

Recommendations. Based on the study findings, the student researcher recommended that future studies that plan to analyze spiritual well-being and/or the 
prison population on the yoga meditation intervention to have a much larger sample size. This would give a better sample representative of the California prison population. It is also ideal to have better control of the groups by implementing pre-surveys and postsurveys. Setting a timeline would also help conduct better future studies. For example, researchers should administer the surveys at the beginning of the year and then administering the post-survey at the end of the year. This would provide a better distinction of whether there is a difference between the experiment and control group. Future researchers that plan to conduct a qualitative study should consider using qualitative data analysis software.

Convenience sampling was utilized for this study, but it is also highly recommended for future researchers to imply random sampling. Future studies should develop a better set of interview questions that focus more on the intervention outcomes. Finally, it would be recommended to collect demographic data on participants' religious belief and identification of being spiritual. This may help better understand if this can affect the SWB scores or not. 


\section{References}

Baetz, M., Bowen, R., Jones, G., \& Koru-Sengul, T. (2006). How spiritual values and worship attendance relate to psychiatric disorder in the Canadian population. Canadian Journal of Psychiatry, 51,654-661. Retrieved from http://search.ebscohost.com/login.aspx?direct=true \&db=aph\&AN=22710447\&sit $\underline{\mathrm{e}=\text { ehost-live }}$

Belavich, T. G. \& Paragment, K. I. (2002). The role of attachment in predicting spiritual coping with a loved one in surgery. Journal of Adult Development, 9, 13-29. Retrieved from http://search.ebscohost.com/login.aspx?direct=true \&db=aph\&AN=11304123\&sit $\underline{\mathrm{e}=\text { ehost-live }}$

Bellamy, C. D., Janett, N. C, Mowbray, O., MacFarlane. P., Mowbray. C. T., \& Holter., M. C. (2007). Relevance of spirituality for people with mental illness attending consumer-centered services. Psychiatric Rehabilitation Journal, 30, 287-294.

Bliss, D. L. (2009). Ethnic differences in spirituality in a sample of men and women in diverse substance abuse treatment settings: Implications for practitioners. Journal of Ethnicity in Substance Abuse, 8, 413 - 430. doi: 10.1080/15332640903327583

Boivin, M.J., Kirby, A.L., Underwood, L.K., \& Silva, H. (1999). Scales of spirituality and mysticism. In P.C. Hill \& R.W. Hood Jr. (Ed.), Measures of religiosity (pp. 1- 531). Birmingham, Al: Religious Education Press.

Bond, K., Ospina, M. B., Hooton, N., Bialy, L., Dryden, D. M., Buscemi, N., \& Carlson, L. E. (2009). Defining a complex intervention: The development of demarcation criteria for "meditation". Psychology of Religion and Spirituality, 1, 129-137. doi: $10.1037 / \mathrm{a} 0015736$

Brown, R.P. \& Gerbarg, P.L. (2005). Sudarshan Kriya Yogic breathing in the treatment of stress, anxiety, and depression: Part II-Clinical applications and guidelines. The Journal of Alternative and Complementary Medicine, 11(4), 711 - 717.

Carlson, B. E., \& Larkin, H. (2009). Meditation as a coping intervention for treatment of addiction. Journal of Religion \& Spirituality in Social Work, 28(4), 379-392. doi: 10.1080/15426430903263260 
Chiesa, A., \& Serretti, A. (2009). Mindfulness-based stress reduction for stress management in healthy people: A review and meta-analysis. Journal of Alternative \& Complementary Medicine, 15(5), 593-600. doi: 10.1089/acm.2008.0495

Dale, G. A. (1996). Existential phenomenology: Emphasizing the experience of the athlete in sport psychology research. The Sport Psychologist, 10, $307-321$.

Dale, G.A. (2000). Distractions and coping strategies of elite decathletes during their most memorable performances. The Sport Psychologist, 14, $17-41$.

Denzin, N. K., \& Lincoln, Y. S. (2006). The state of qualitative inquiry. International Journal of Qualitative Studies in Education, 19(6), 769-782. doi: $10.1080 / 09518390600975990$

Derezotes, D. (2000). Evaluation of yoga and meditation trainings with adolescent sex offenders. Child and Adolescent Social Work Journal, 17(2), 97 - 113.

Drayer, J. Shapiro, S.L., Dwyer, B., Morse, A.L., \& White, J. (2010). The effects of fantasy football participation on NFL consumption: A qualitative analysis. Sport Management Review, 13, 129-141.

Ellison, C.W., \& Paloutzian, R.F. (2009). LifeADVANCE. Welcome to the home of the Spiritual Well-Being Scale. Retrieved September 2011, from http://www.lifeadvance.com

Ellison, C. G. \& Smith, J. (1991). Toward an integrative measure of health and wellbeing. Journal of Psychology and Theology, 19(1), $35-48$.

Fox, R. J. (1997). Women, nature and spirituality: A qualitative study exploring women's wilderness experience. In D. Rowe \& P. Brown (Eds.), Proceedings, ANZALS conference 1997 (pp. 59-64). Newcastle, NSW, Australia: Australian and New Zealand Association for Leisure Studies, and Department of Leisure and Tourism Studies, The University of Newcastle. 
Francis, T. (1991). Meditation as an alternative to substance misuse: A current review. Therapeutic Recreation Journal, 25(4), 50 - 60.

Gim, J. (2009). Toward a quality leisure experience: The practice of mindfulness. World Leisure, 51(2), $105-109$.

Grant, A. (2007). Spirituality, health and the complementary medicine practitioner. Journal of Australian Traditional-Medicine Society, 13(4), 207 - 209. Retrieved from http://search.ebscohost.com/login.aspx?direct=true \&db=aph\&AN=28161953\&sit $\underline{\mathrm{e}=\text { ehost-live }}$

Gratton, C. \& Jones, I. (2004). Analyzing data II: Qualitative data analysis. In C. Gratton \& I. Jones, Research methods for sport studies (pp. 217 -227). New York: Routledge.

Gross-Schaefer, A. (2009). Reaching for the stars: Effective tools for the creation of a more spiritual workplace. Employee Relations Law Journal (00988898), 35(1), 25-42. Retrieved from http://search.ebscohost.com/login.aspx?direct=true\&db=s3h\&AN=43248516\&sit $\underline{\mathrm{e}=\text { ehost-live }}$

Gomez, R. \& Fisher, J. W. (2003). Domains of spiritual well-being and development and validation of the Spiritual Well-Being questionnaire. Personality and Individual Differences, 35(8), 1975 - 1991. doi: 10.1016/S0191-8869 (03) 00045-X

Goodnow, J. M., \& Ruddell, E. (2009). An illustration of the quest genre as spiritual metaphor in adventure travel narratives. Leisure/Loisir: Journal of the Canadian Association for Leisure Studies, 33(1), 241-267. Retrieved from http://search.ebscohost.com/login.aspx?direct=true \&db=s3h\&AN=44267764\&sit $\underline{\mathrm{e}=\text { ehost-live }}$

Griffin, J. \& LeDuc, J. (2009). Out of the fish tank: The impact of adventure programs as a catalyst for spiritual growth. Leisure/Loisir: Journal of the Canadian Association for Leisure Studies, 33(1), 197-215. Retrieved from http://search.ebscohost.com/login.aspx?direct $=$ true $\& d b=s 3 h \& A N=44267762 \&$ sit $\underline{\mathrm{e}=\text { ehost-live }}$ 
Groff, D., Battaglini, C., Sipe, C., O’Keefe, C., \& Peppercorn, J. (2009). Lessons from breast cancer survivors: The role of Recreation Therapy in facilitating spirituality and well-being. Leisure/Loisir: Journal of the Canadian Association for Leisure Studies, 33(1), 341-365. Retrieved from http://search.ebscohost.com/login.aspx?direct=true \&db=s3h\&AN=44267768\&sit $\underline{\mathrm{e}=\text { ehost-live }}$

Hawks, S. (1994). Spiritual health: Definition and theory. Wellness Perspectives, 10, 313.

Heintzman, P., \& Mannell, R. C. (2003). Spiritual functions of leisure and spiritual wellbeing: Coping with time pressure. Leisure Sciences, 25(2), 207-230. Retrieved from http://articles.sirc.ca/search.cfm?id=S-889325: http://search.ebscohost.com/login.aspx?direct=true\&db=s3h\&AN=SPHS889325\&site=ehost-live; http://articles.sirc.ca/search.cfm?id=S-889325: http://www.gbhap.com/

Heintzman, P. (2002). A conceptual model of leisure and spiritual well-being. Journal of Park and Recreation Administration, 20(4), 147-169.

Heintzman, P. (2007a). Men's wilderness experience and spirituality: A qualitative study. In R. Burns \& K. Robinson (Comps.), Proceedings of the 2006 Northeastern Recreation Research Symposium (pp. 432-439) (Gen. Tech. Rep. NRS-P-14). Newton Square, PA: U.S. Department of Agriculture, Forest Services, Northern Research Station.

Heintzman, P. (2008). Leisure-spiritual coping: A model for Therapeutic Recreation and leisure services. Therapeutic Recreation Journal Special Issue, 42(1), 56- 73. Retrieved from http://search.ebscohost.com/login.aspx?direct=true\&db=s3h\&AN=32518839\&sit $\underline{\mathrm{e}=\text { ehost-live }}$

Heintzman, P. (2009). The spiritual benefits of leisure. Leisure/Loisir, 22, $419-445$. Retrieved from http://search.ebscohost.com/login.aspx?direct=true \&db=s3h\&AN=44267771\&sit $\underline{\mathrm{e}=\text { ehost-live }}$

Heintzman, P. (2010). Nature-based recreation and spirituality: A complex relationship. Leisure Sciences, 32, 72 - 89. doi: 10.1080/01490400903430897 
Henderson, K. A., Oakleaf, L., \& Bialeschki, M. D. (2009). Questions raised in exploring spiritual growth and camp experiences. Leisure/Loisir: Journal of the Canadian Association for Leisure Studies, 33(1), 179 -195. Retrieved from http://search.ebscohost.com/login.aspx?direct=true \&db=s3h\&AN=44267761\&sit $\underline{\mathrm{e}=\text { ehost-live }}$

Herriot, E. N., Schmidt-Wilk, J., \& Heaton, D. P. (2009). Spiritual dimensions of entrepreneurship in Transcendental Meditation and TM-Sidhi program practitioners. Journal of Management, Spirituality \& Religion, 6(3), 195 - 208.

Howe-Murphy, R. \& Murphy, J.F. (1987). An exploration of the new age consciousness paradigm in Therapeutic Recreation. In Philosophy of Therapeutic Recreation: Ideas and issues. Alexandria, VA: National Therapeutic Recreation Society \& National Recreation and Park Association.

Iwasaki, Y., Bartlett, J.D., Gottlieb, B., Hall, D. (2009). Leisure-like pursuits as an expression of aboriginal cultural strengths and living actions. Leisure Science, 31, 158 - 173. Retrieved from http://search.ebscohost.com/login.aspx?direct=true\&db=s3h\&AN=36591539\&sit $\underline{\mathrm{e}=\text { ehost-live }}$

Joblin, D. (2009). Leisure and spirituality: An engaged and responsible pursuit of freedom in work, play, and worship. Leisure/Loisir: Journal of the Canadian Association for Leisure Studies, 33(1), 95 -120. Retrieved from http://search.ebscohost.com/login.aspx?direct=true \&db=s3h\&AN=44267758\&sit $\underline{\mathrm{e}=\text { ehost-live }}$

Mannell, R. C., \& Kleiber, D. A. (1997). A social psychology of leisure. State College, PA: Venture Publishing, Inc.

Martsolf, D.S., \& Mickley, J.R. (1998). The concept of spirituality in nursing theories: Differing world-views and extent of focus. Journal of Advanced Nursing, 27, 294 -303 .

Maxwell, J.A. (2005). Validity: How might you be wrong? In J.A. Maxwell, Designing qualitative research: An interpretative approach $\left(2^{\text {nd }}\right.$ ed., pp. $\left.105-116\right)$. Thousand Oaks: Sage. 
McDonald, B., \& Schreyer, R. (1991). Spiritual benefits of leisure participation and leisure settings. In B. Driver, P. Brown \& G. Peterson (Eds.), Benefits of leisure (pp. 179-194). PA: Venture Publishing.

Mela, M. A., Marcoux, E., Baetz, M., Griffin, R., Angelski, C., \& Deqiang, G. (2008). The effect of religiosity and spirituality on psychological well-being among forensic psychiatric patients in Canada. Mental Health, Religion and Culture, 11 (5), $517-532$.

Mystakidou, K., Tsilika, E., Parpa, E., Hatzipli, I., Smyrnioti, M., Galanos, A., \& Vlahos, L. (2008). Demographic and clinical predictors of spirituality in advanced cancer patients: A randomized control study. Journal of Clinical Nursing, 17, 1779 1785. doi: $10.1111 / \mathrm{j} .1365-2702.2008 .02327 . \mathrm{x}$

N. Richeson (personal communication, October 7, 2010).

Nagla, M. (2006). Yoga, health and leisure: Attitudes of women in Harayana. World Leisure, 48(2), 23- 33.

Nagy Hesse-Biber, S. \& Leavy, P. (2011). Chapters 1 \& 2. In N. Hesse-Biber \& P. Leavy, The practice of qualitative research $\left(2^{\text {nd }}\right.$ ed., pp. $\left.3-30\right)$. Los Angeles: Sage.

Ortlipp, M. (2008). Keeping and using reflective journals in the qualitative research process. The Qualitative Report, 13(4), 695-705.

Paloutzian, R. F., \& Ellison, C. W. (1982). Loneliness, spiritual well-being, and quality of life. In L. A. Peplau \& D. Perlman (Eds.), Loneliness: A source book of current theory, research, and therapy (pp. 224-237). New York: Wiley Interscience.

Parry, D. C. (2009). Dragon Boat Racing for breast cancer survivors: Leisure as a content for spiritual outcomes. Leisure/Loisir: Journal of the Canadian Association for Leisure Studies, 33(1), 317 - 340. Retrieved from

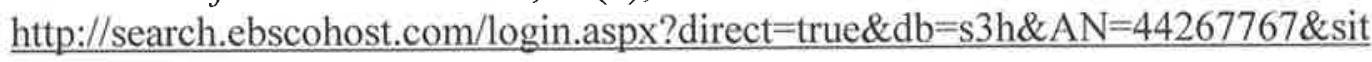
$\underline{\mathrm{e}=\text { ehost-live }}$ 
Peace, T. G.M. (2009). Journeying by canoe: Reflections on the Canoe and spirituality. Leisure/Loisir: Journal of the Canadian Association for Leisure Studies, 33(1), 217-239. Retrieved from http://search.ebscohost.com/login.asp $x$ ?direct=true \&db=s3h\&AN=44267763\&sit $\underline{\mathrm{e}=\text { ehost-live }}$

Phillips, J. (2001). Cultural construction of manhood in prison. Psychology of Men \& Masculinity, 2 (1), 13-23. doi: 10.1037/1524-9220.2.1.13

Schmidt, C. \& Little, D. E. (2007). Qualitative insights into leisure as a spiritual experience. Journal of Leisure Research, 39(2), 222- 247. Retrieved from http://search.ebscohost.com/login.aspx?direct $=$ true \&db=s3h\&AN=25246743\&sit $\underline{\mathrm{e}=\text { ehost-live }}$

Schulz, E. K. (2005). The meaning of spirituality for individuals with disabilities. Disability and Rehabilitation, 27(21), 1283 - 1295. Retrieved from http://search.ebscohost.com/login.aspx?direct=true \&db=s3h\&AN=18947364\&sit $\underline{\mathrm{e}=\text { ehost-live }}$

State of California Department of Corrections and Rehabilitation, (2010). Average daily prison population (IPOP-2). Retrieved from website: http://www.cdcr.ca.gov/Reports_Research/Offender_Information_Services_Branc $\underline{\mathrm{h} / \mathrm{index} \cdot \mathrm{html}}$

Stenius, K., Mkela, K., Miovsky, M., \& Gabrhelik, R. (2008). How to write a publishable qualitative research In T. Babor, K. Stenius \& S. Savva (Eds.), In Publishing Addiction Science: A Guide for the Perplexed (2nd ed., pp. 82 - 97). Retrieved from http://www.parint.org/isajewebsite/isajebook2.htm

Stumbo, N. (2009). Professional issues in Therapeutic Recreation: On competence and outcomes $\left(2^{\text {nd }}\right.$ ed.). Champaign, IL: Sagamore Publishing.

Stringer. L. A., \& McAvoy, L. H. (1992). The need for something different: Spirituality and the wilderness adventure. The Journal of Experiential Education, $15(1), 13$ 21. 
Szalavitz, M. (2010, December 23). Explaining why mediators may live longer. Time Magazine. Retrieved from http:/healthland.time.com/2010/12/23/couldmeditation-extend-life-intriguing-possibility-raised-by-newstudy/\#ixzz1B3fD0mTR

T. Butryn \& J. Chin (personal communication, September 20, 2010)

Vohra-Gupta, S., Russell, A., \& Lo, E. (2007). Meditation: The adoption of eastern thought to western social practices. Journal of Religion \& Spirituality in Social Work, 26(2), 49-61. doi: 10.1300/J377v26n02-03

Zinnbauer, B. J., Pargament, K. I., Cole, B., Rye, M. S., Butter, E. M., Belavich, T. G., Hipp, K. M., Scott, A. B \& Kadar, J. L. (1997). Journal for the Scientific Study of Religion, 36(4), 549-564. 
Appendix A

\section{Modified Spiritual Well-Being Scale}

\section{Modified Spiritual Well-Being Scale}

For each of the following statements circle the choice that best indicates the extent of your agreement or disagreement as it describes your personal experience:

$$
\begin{aligned}
\mathrm{SA} & =\text { Strongly Agree } & \mathrm{D}=\text { Disagree } \\
\mathrm{MA} & =\text { Moderately Agree } & \mathrm{MD}=\text { Moderately Disagree } \\
\mathrm{A} & =\text { Agree } & \mathrm{SD}=\text { Strongly Disagree }
\end{aligned}
$$

1. I don't find much satisfaction in private prayer with the divine. SA MA A D MD SD

2. I don't know who I am, where I came from, or where I'm going. SA MA A D MD SD

3. I believe that the divine loves me and cares about me. $\quad$ SA MA A $\quad$ D

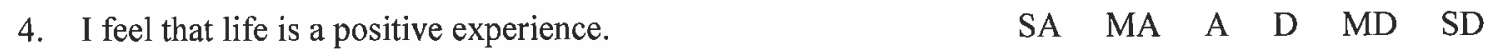

5. I believe that the divine is impersonal and not interested in my daily situations. SA MA A D $\quad$ MD SD

6. I feel unsettled about my future. $\quad$ SA MA A D MD SD

7. I have a personally meaningful relationship with the divine. $\quad$ SA $\quad$ MA A $\quad$ D $\quad$ MD SD

8. I feel very fulfilled and satisfied with life. $\quad$ SA

9. I don't get much personal strength and support from the divine. SA MA A $\quad$ D $\quad$ MD SD

10. I feel a sense of well-being about the direction my life is headed in. SA MA A D MD SD

11. I believe the divine is concerned about my problems. $\quad$ SA MA A D MD SD

12. I don't enjoy much about life. $\quad$ SA MA A D MD SD

13. I don't have a personally satisfying relationship with the divine. SA MA A D MD SD

14. I feel good about my future. $\quad$ SA

15. My relationship with the divine helps me not to feel lonely. SA MA A D MD SD

16. I feel that life is full of conflict and unhappiness. $\quad$ SA

17. I feel most fulfilled when I'm in close communion with the divine. SA MA A D $\quad$ MD SD

18. Life doesn't have much meaning. $\quad$ SA MA A D

19. My relation with the divine contributes to my sense of well-being. $\quad$ SA MA A D MD SD

20. I believe there is some real purpose for my life. $\quad$ SA MA A $\quad$ D MD SD 


\section{Appendix B}

\section{Demographic Data Sheet}

\section{Demographic Data Sheet}

Code name \#

1. Full name:

Directions: Please complete this to the best of your knowledge. Circle the letter(s) that correlates to your answer. The information will be kept confidential and will only be accessible by the student researcher, Kim Pham.

2. Gender:
a. Male

b. Female

3. Age:
a. $18-24$
b. $25-30$
c. $31-40$
d. $41-54$
e. $55-64$
f. 65 or older

4. Race/Ethnicity: Circle all that applies
a. Hispanic, Latino, or Spanish
b. White
c. Black, African American
d. American Indian or Alaska Native
e. Asian Indian
f. Japanese
g. Native Hawaiian
h. Chinese
i. Korean
j. Guamanian or Chamorro
k. Filipino
1. Vietnamese
m. Samoan
n. Other Asian
i. Please specify:
o. Other Pacific Islander
ii. Please specify:

5. Time in incarceration:
a. Less than 6 months
b. 6 months -1 year
c. 1-5 years
d. 6-10 years
e. $11-15$ years
f. 16-Lifetime
g. Other
iii. Please specify: 
Appendix C

Interview Guide

Interview Guide

1. Introduction

- Interviewer's role

- Purpose of interview

- Informed Consent Form

2. Background - information not addressed from the demographic data sheet

- Condition history

- Questions about emotional health, physical health, social health, and spiritual health

3. Describe your experience of being a prison inmate (relative to your spirituality) before you participated in the PYP.

4. Do you find your life meaningful? How so?

5. What values and beliefs do you cherish and live by?

6. Do you have any desires/wishes/goals for yourself?

7. Have you experienced awareness of something that is bigger or beyond yourself? The Divine? God(s)? Spirit?

8. Have you experience connection to yourself, to others, to the environment, and/or God/Spirit/Divine?

9. Do you have a sense of who you are now? Have you experienced self-reflection?

10. When does spirituality [reflection] occur for you?

11. Do you find the PYP to be conducive to your (spiritual) well-being?

12. How is your (spiritual) experience in the prison after participating in the PYP? 


\section{Appendix D}

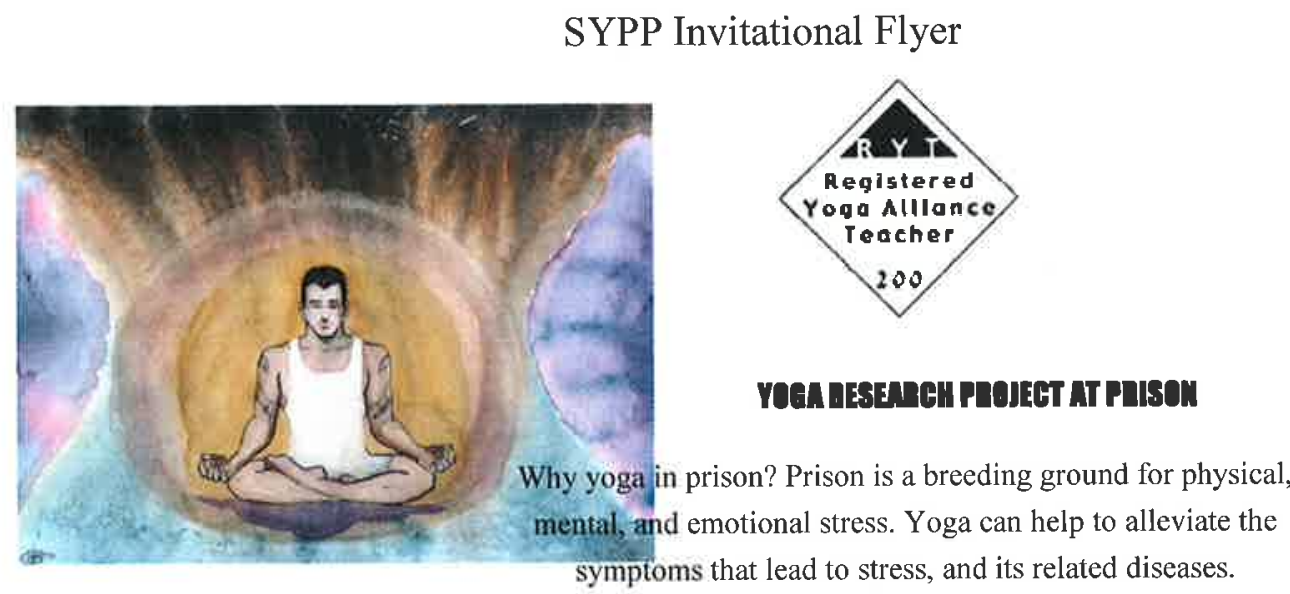

Yoga can help to transform reactive behaviors that may have been

\section{A PATH FOR formed through dissociation and neglect. A regular practice can free REHABILITÁMntal Health the mind from confusion and cultivate self-awareness and control}

Yoga is also a great workout mentally and physically. Many of the

\author{
"Yoga, an ancient \\ but perfect science, \\ deals with the \\ evolution. This \\ evolution involves \\ all aspects of one's \\ being, from bodily \\ health to self \\ realization"-BKS \\ lyengar
}

world's top athletes practice yoga for benefits.

Sign up below or send a request to:

L2 Mental Health. Therapist Munshi

\section{SIGNUP}

1.

6.

2.

7.

3.

8.

4.

9.

5.

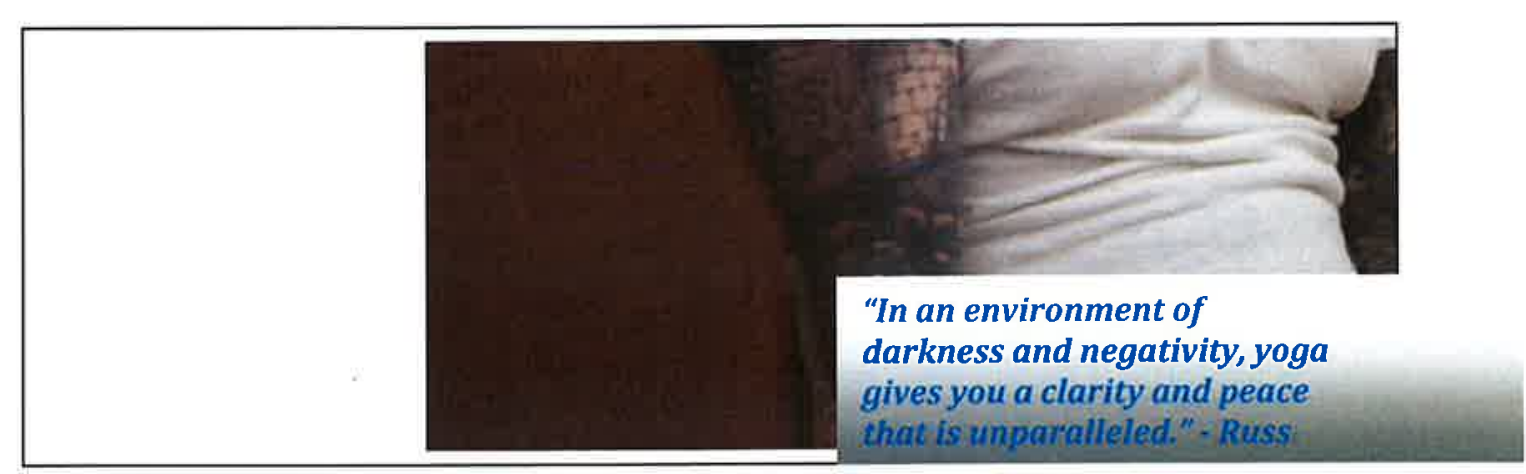


Appendix D (continued)
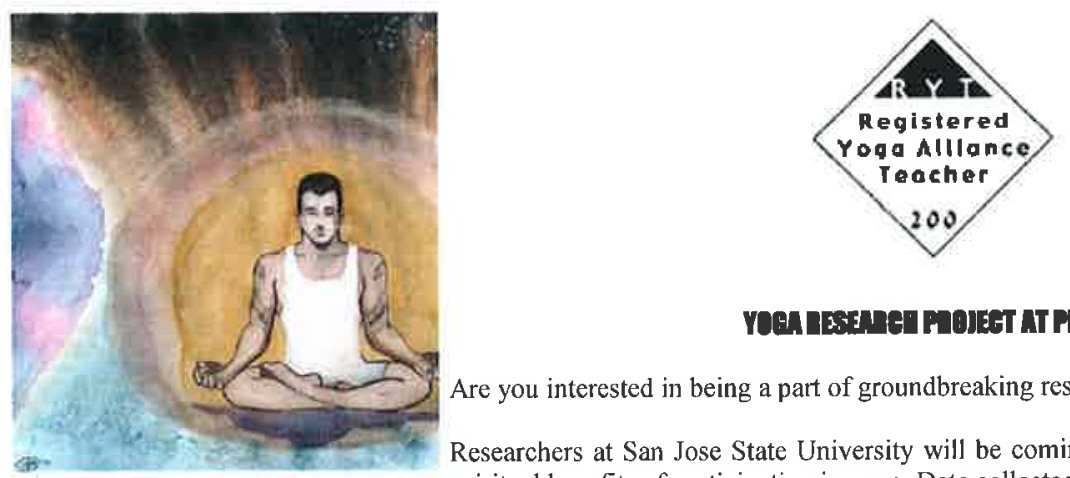

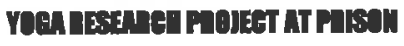

Are you interested in being a part of groundbreaking research here at (prison)?

Researchers at San Jose State University will be coming to DVI in order to study the spiritual benefits of participating in yoga. Data collected will help to gain understanding of how spirituality can affect our health.

\section{A PATH FOR \\ Participants will be asked to fill out a questionnaire and may be interviewed by the researcher. Involvement in the yoga program at DVI is not a requirement for participation in the study.} REHABILMTEATLITHa

Sign up below or send a request to:

L2 Mental Health. Therapist Munshi

\section{SIGNUP}

1.

6.

2.

7.

"Yoga, an ancient

3.

3.

8.

4.

9.

evolution. This

5.

all aspects of one's being, from bodily health to self realization"-BKS Iyengar

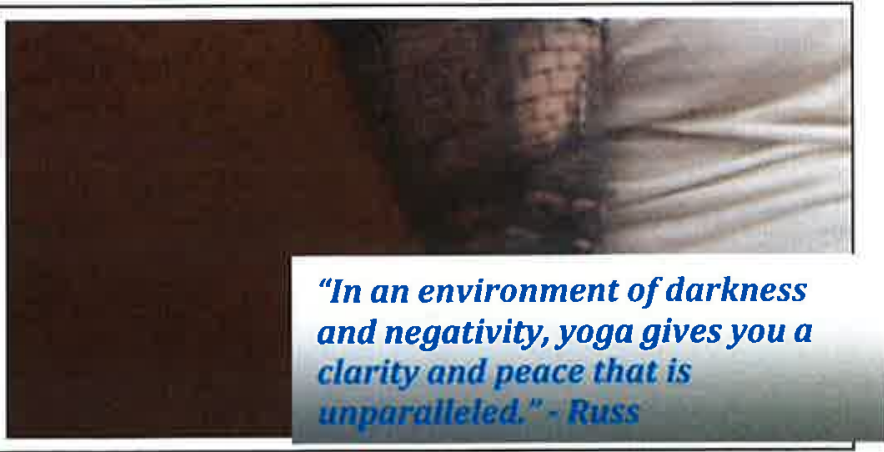




\section{Appendix E}

\section{SJSU Informed Consent Form}

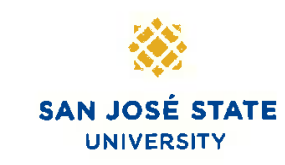

College of Applied

Sciences and Arts

Department of Hospitality, Recreation \& Tourism Management

One Washington Square San Jose, California 95192-0211

Direct: 408-924-3000

Fax: 408-924-3061

www.sjsu.edu/hrtm

www spsuedu
Informed Consent Form

Agreement to Participate in Research

Name of researchers: Kim Pham, SISU Student Researcher, Dr. Susan Ross. Ph.D., CTRS, RTC, and Swapan Munshi. CTRS. RYT

Title of Study: Outcomes of Recreation Therapy Interventions of Yoga and Meditation on Prison Inmates' Spiritual Well-Being

1.) You have been asked to participate in a research that is evaluating whether you are experiencing outcomes of spiritual well-being. The overall goal of this research is to contribute to the scholarly discourse in the field of Recreational Therapy by clarifying the spiritual aspects of interventions specifically designed and facilitated to affect spiritual health and well-being. This valuable information will contribute to the field of recreational therapy to help improve services for clients.

2.) You are being asked to participate in this research by either being interviewed and/or completing the Spiritual Well-Being Scale (SWBS) and the demographic data sheet. If you are being interviewed, the Recreational Therapist or the student researcher will set up a time and location based on availability. An interview gujde will be given to you in order to allow you time to reflect, contemplate, and even prepare your thoughts/responses in regards to your experiences on spiritual well-being through leisure. It will be a face-to-face, semi-formal, and audio-recorded. Each interview time frame will be determined on how much information you share. The student researcher or the Recreational Therapist will administer the demographic data sheet and the Spiritual Well-Being Scale (SWBS). The SWBS is a selfadministered, pencil-and-paper survey that will take only 10-15 minutes to complete. For both the interview and the SWBS survey, you will be allowed to choose a code/nick name to ensure confidentiality.

3.) Risks that may rise from participating in this study are psychological or emotional discomfort. Research and/or survey questions may raise or trigger your past memories, personal unresolved issues, or political/value system dissonance.

4.) Benefits from this research may include the possibility of psychosocial benefits for you because this research may allow you to reflect on your experiences that may elicit a positive outlook on yourself and your wellbeing, but this is not guaranteed.

This research may contribute to the field of Recreational Therapy because the data that will be collected will better understand the relationship of leisure and spiritual well-being might help inform Recreational Therapists on how to better facilitate spiritual-based interventions for clients in the field of health care.

Initials 


\section{Appendix E (continued)}

\section{0 \\ SAN JOSÉ STATE UNIVERSITY}

College of Applied Sciences and Arts

Department of Hospitality, Recreation \& Tourism Management

One Washington Square San José, Californa 95192-0211 Direct: 408-924-3000 Fax: 408-924-3061 www sssu.edu/hrtm

5.) Although the data and the results of this research may be published, no information that could identify you will be included. If published, your identity will be sealed and referred to by another name chosen by the student researcher, not by your chosen code/nick name; therefore, neither you or anyone will be able to identify who you are in the study except for the student researcher. Your identity will be kept confidentially and only the student researcher will have access to the personal information you share.

6.) There is no compensation from participating in this research.

7.) Questions about this research may be addressed to Dr. Susan Ross, Ph.D., CTRS, RTC at susan.ross@sjsu.edu. Complaints about the research may be presented to Dr. Randy J. Virden, Ph.D., Department Chair of the Hospitality, Recreation, and Tourism Management, College of Applied Sciences and Art, al randy.virden@sjsu.edu or (408) 924-3199. Questions about a research subjects' rights, or research-related injury may be presented to Pamela Stacks, Ph.D., Associate Vice President, Graduate Studies and Research, at (408) 924-2427.

8.) No service of any kind, to which you otherwise are entitled, will be lost or jeopardized if you choose to nol participate in the study.

9.) Your consent is being given voluntarily. You may refuse to participate in the entire study or in any part of the study. If you are completing the SWBS survey and/or being interview, you have the right to not answer any questions you do not wish to answer. If you decide to participate in the study, you are free to withdraw at any time without any negative effect on your relations with San Jose State University or with Deuel Vocational Institution Prison.

10.) At the time that you sign this consent form, you will receive a copy of it for your records, signed and dated by the investigator(s) (either the student researcher or the Recreational Therapist).

* The signature of a subject on this document indicates agreement to participate in the study.

*The signature of a researcher on this document indicates agreement to include the above named subjects in the research and attestation that the subject has been fully informed of his or her rights.

Subject's Signature

Investigator's Signature
Date

Date 
Appendix F

CPHS Informed Consent Form

Official Title of Project: "Outcomes of Recreational Therapy Interventions of Yoga and Meditation on Prison Inmates' Spiritual Well-Being"

Principal Investigator: Kim Hoang Pham, Graduate student researcher

Institution Conducting the Research: $\underline{\text { San Jose State University }}$

The required elements details that must be addressed in each section below may be found in the CPHS Instructions for Researchers link:

\section{Purpose, Participation, and Procedures of the study}

The purpose of this research is to analyze a Recreational Therapy yoga and meditation intervention called the Prison Yoga Project (PYP) at a California prison to determine whether the subjects are experiencing outcomes of spiritual well-being, which may or may not be due to participating in three interventions: (a) Pranayama (breathing exercises), (b) yoga, and (c) chakra meditation. The research question is: What are the outcomes of yoga and meditation facilitated by Recreation Therapy on prison inmates' spiritual well-being? The goal is to contribute to the scholarly discourse in the field of Recreational Therapy and to produce preliminary outcomes data by clarifying the spiritual aspects of interventions specifically designed and facilitated to affect spiritual health and well-being.

Participants will be selected from within the Deuel Vocational Institution (DVI)

Prison population, comprised exclusively of adult male inmates. The age of the subjects will range from 18 years old and up.

This investigation will use a mixed-method approach that includes a quantitative standardized instrument and qualitative method of semi-structured interviews. The design aims to solicit a total of 40 subjects to participate in the experimental group and 40 subjects in the control group.

Subjects in the experimental group will be those who have or are still participating in Recreational Therapy PYP interventions and are willing to complete a demographic data sheet and the quantitative instrument-a Spiritual Well-Being Scale (SWBS)and to be interviewed. Subjects in the control group are those who have never attended the PYP and are willing to complete the SWBS.

Only the student researcher and/or the Recreational Therapist will collect all of the research data. Each subject will be given two copies of the Informed Consent Form from the student researcher or the Recreational Therapist. Two copies will be 
distributed so that one signed copy is for the subject and the second signed copy is for the student researcher's records. The student researcher or the Recreational Therapist will explain and answer any questions the subjects may have. The subjects will be allowed to choose a code name to ensure confidentiality.

The qualitative data will be collected only from the experimental group. Convenience sampling will be used to recruit inmates who are willing to be interviewed by the student researcher and Dale (2000) recommends interviewing subjects who can provide a variety of perspectives on the spiritual well-being experiences from participating in the PYP. The interview will ask subjects to share their experiences before and after Recreational Therapy yoga interventions.

For the quantitative portion of the study, the student researcher or the Recreational Therapist will administer the demographic data sheet and the SWBS to the subjects. This is a self-administered, pencil-and-paper survey that will take 10-15 minutes to complete (Heintzman \& Mannell, 2003; Boivin, Kirby, Underwood, \& Silva, 1999; Bliss, 2009). For the experimental group, the surveys will be administered to all of the subjects who have completed at least three PYP sessions. For the control group, the Recreational Therapists and the student researcher will use a systematic random sampling, which they will contact every other inmate who have participated in Recreation Therapy, but have never participated in the PYP.

The interviews will be face-to-face, semi-structured, and audio-recorded. An interview guide will be given to each interviewee in order to allow the interviewee time to reflect, contemplate, and even prepare their thoughts/responses (T. Butryn \& J. Chin, personal communication, September 20, 2010). Each interview may last from 1 to 3 hours depending on the subject (Dale, 1996, 2000). The interview appointment will be scheduled ahead of time according to the interviewer's and the interviewee's availability. DVI determines the location. Data will be analyzed using an existential-phenomenological approach in order to examine personal, subjective experiences and phenomenon (Nagey Hesse-Biber, 2011; Dale, 1996, 2000). The student researcher will conduct all of the interviews. Once interview transcripts are transcribed verbatim, subjects will be asked to validate their responses through member checks (Dale, 1996; Gratton \& Jones, 2004; Maxwell, 2005).

\section{Description of Risks to the Participants}

There may be psychological or emotional discomfort due to the interview questions, SWBS questions and/or the demographic data sheet. Given the inmates' history of violence or impulsivity and their incarcerated context, questions on these instruments may raise or trigger past painful memories, unresolved issues, or political/value system dissonance.

\section{Description of the Measures to be Taken to Ensure Participant Confidentiality}


A demographic data sheet will ask subjects to state their full name, age, race/ethnicity, level of education, and time served in prison. This will be supplemented with the SWBS. Subjects will choose a code name to ensure confidentiality. The code names will be written on their own interview transcripts, a demographic data sheet, and a SWBS. A separate list of the code names and the subjects' real name will only be available to the student researcher; this code name list will be kept in the student researcher's home in a locked cabinet along with the subjects' interview transcripts, demographic data sheets, and completed SWBS instruments for up to three years after publication. The code names will be the only identification that will be available for inspection, if required. If this study is published, no identifiable or traceable characteristics, traits or behaviors will be described that could possibly allow a reader to trace the described traits back to an individual inmate. Also, if published, pseudonyms will be used. Once published, the code names list will be destroyed thoroughly after three years by permanently deleting or shredding it.

Interview transcripts, demographic data sheets, audiotapes, and the SWBS instruments will be locked in the student researchers' home for up to three years after the thesis is completed. Only the student researcher will have access to the interview transcripts, demographic data sheets, SWBS, and the code names list.

\section{Description of any Benefits to Participants from participation in this Study}

There may be the possibility of psychosocial benefits for participants because this study will allow the participants to reflect on their experiences, which may elicit a positive outlook on themselves and their well-being. Participation in this study might give the inmate the perception of enacting 'good behavior' that they perceive might help advance towards early parole. It is desirable that inmates participate in this study because their shared experiences will contribute to the knowledge that may improve their own Recreational Therapy services and develop the understanding of the relationship between leisure and spirituality.

This research also may generally contribute to the field of Recreational Therapy, health services, and complementary and alternative medicine by revealing knowledge that links the relationship between leisure and spirituality, spiritual well-being, and interventions to facilitate spiritual health for clients who receive health care.

\section{Alternative Procedures or Treatments to this Study}

N/A

6. Compensation for Participant related to this Study 
Subjects will not receive compensation for their participation in this research study.

\section{Treatment for Injury related to this Study}

If there is a risk of emotional discomfort, the DVI prison will have qualified personnel within the facility that can respond to a participant's psychological and physical needs.

\section{Potential Conflict of Interest of the Researchers}

The primary investigator is a current volunteer at the DVI. I am conducting this graduate studies related project under the supervision of Recreational Therapist Swapan Munshi; I have no financial interest within this institution. This institution was chosen for my master's thesis research, not because I wish to obtain a job there or for any reason other than the fact that this specific recreational therapist facilitates the intervention of Yoga with a spiritual theme.

9. Contacts for Participant Questions about this study

Questions about this research may be addressed to Dr. Susan Ross, Ph.D., CTRS, RTC at susan.ross@sjsu.edu. Complaints about the research may be presented to Dr. Randy J. Virden, Ph.D., Department Chair of the Hospitality, Recreation, and Tourism Management, College of Applied Sciences and Art, at randy.virden@sjsu.edu or (408) 924-3199. Questions about a research subjects' rights, or research-related injury may be presented to Pamela Stacks, Ph.D., Associate Vice President, Graduate Studies and Research, at (408) 924-2427.

\section{Voluntary Participation in this Study}

The participants' consent is being given voluntarily. They may refuse to participate in the entire study or in any part of the study. If any subjects choose to not participate in the research at any time, they will not be subjected to any adverse effects. If they are completing the SWBS survey and/or being interview, they have the right to not answer any questions that they do not wish to answer. If they decide to participate in the study, they are free to withdraw at any time without any negative effect on their relations with San Jose State University or with Deuel Vocational Institution Prison.

\section{Research Participant's Bill of Rights Provided to Participants}


Permission has been sought and granted by the Warden of DVI, Mrs. S.M. Salinas, and the Deputy Director of the Office of Research, Brenda Grealish, to allow for this stated analysis to be conducted with the DVI inmates. If an inmate wishes to participate in this investigation, the Recreational Therapist will verbally review everything that is written in the Informed Consent Form and then provide two copies of the Informed Consent Form that will describe what the subject can expect if they choose to commit to participation. The Informed Consent Forms will only be available in English. If the inmate chooses to participate in the investigation, the Recreational Therapist/ student researcher and the subject will sign both copies of the Informed Consent Form. Each person will keep a signed copy for his or her own records (please refer to the "Informed Consent Form" copy provided).

Inmates that participate must also sign a CDCR form 146 "Inmate Declaration to News Media Contact," although not media specific, this research will be or has the potential to be placed in print and as such we would need a release from the inmate giving their permission for interview.

The language, tone, and body language that the Recreational Therapist and the student researcher will use will be neutral and detached to any outcome of the subject's decision process. There will be no negative or coercive language used to persuade the inmate to participate in this study.

\section{Consent Statement and Signature}

I give my consent to participate in this research study and have received a copy of the Research Participant's Bill of Rights.

Printed Name of Participant

Signature of Participant

Date

Printed Name of Representative

Signature of Representative

Date 


\author{
Appendix G \\ Participant's Bill of Rights for Non-Medical Research
}

\title{
Participant's Bill of Rights for Non-Medical Research
}

You have been asked to participate in a research study. Any participant in a research study has the right to:

a. Be told the nature and purpose of the study.

b. Be given an explanation of what will happen during the study and of how the research participant is expected to participate.

c. Be given an explanation of any risks or discomforts that may be experienced as a result of participating in the study.

d. Be given an explanation of any benefits that may be expected from participation in the study.

e. Be told of other appropriate choices that may be better or worse than being in the study, and be told of the risks and benefits of those other choices.

f. Have the opportunity to ask questions about the study or about your participation in it, both before agreeing to participate in the study and during the course of the study.

g. Be told that you may withdraw your consent and participation in the study at any time, and that your withdrawal will not affect your services.

h. Be told that you may refuse to answer any question.

i. Be given a copy of the signed and dated consent form.

j. Be free of pressure when considering whether to consent to, and participate in, the study.

k. Be informed, upon request, about the results of the study. 
Appendix G (continued)

\section{Declaración de Derechos de Participantes en estudios Nomedicos \\ (Spanish translation of Participant's Bill of Rights for Non-Medical Research)}

Se le ha pedido que participe en un estudio de investigación. Cualquier participante en un estudio de investigación tiene el derecho a:

a. Que se le diga la naturaleza y el propósito del estudio.

b. Que se le dé una explicación de lo que ocurrirá durante el estudio y de que manera se espera que participe el participante en una investigación.

c. Que se le dé una explicación de todos los riesgos o molestias que pueden ocurrir como resultado de la participación en el estudio.

d. Que se le dé una explicación de todos los beneficios que se pueden recibir de la participación en el estudio.

e. Que se le diga de otras alternativas apropiadas que pudieran ser mejores o peores que la participación en el estudio, y que se le diga de los riesgos y beneficios de esas otras alternativas.

f. Que tenga la oportunidad de hacer preguntas acerca del estudio o acerca de su participación en el estudio, antes de participar en el estudio y durante la duración del estudio.

g. Que se le diga que puede retirar su consentimiento y participación en el estudio en cualquier momento, y que su retiro no le afectará sus servicios.

h. Que se le diga que puede rehusarse a contestar cualquier pregunta.

i. Que se le dé una copia firmada y fechada de la forma de consentimiento.

j. Estar libre de presiones al momento de decidir si da su consentimiento para participar en el estudio.

k. Obtener información, en cuanto usted lo pida, acerca de los resultados del estudio.

(Traducido por J. Ruiz) 


\section{Appendix $\mathrm{H}$}

\section{Inmate Declaration to News Media Contact}

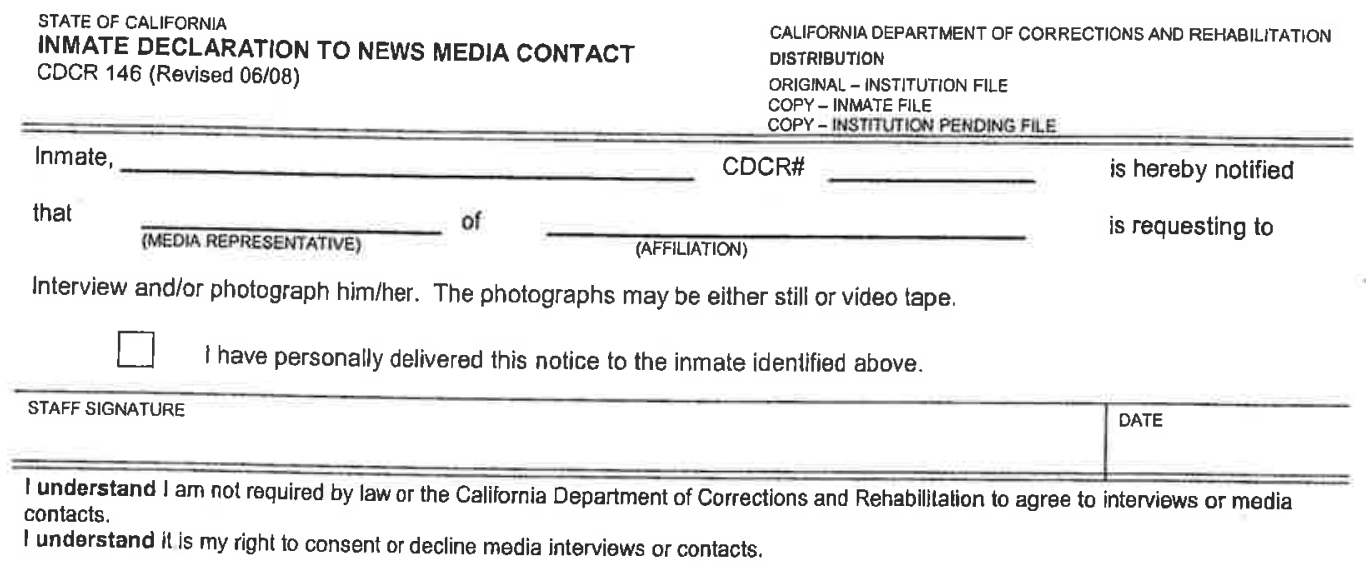

Check the appropriate boxes.

. INMATE DECLINES TO MEDIA CONTACT:

$\square 1$ I decline to be interviewed by this media agency or media representative.

21 decline to be interviewed by any media.

3 I decline to be photographed or filmed.

\section{INMATE CONSENTS TO MEDIA CONTACT:}

$\square$ Undersigned consents to be interviewed.

2 Undersigned consents to be tape recorded.

3 Undersigned consents to be photographed or filmed.

The undersigned on behalf of him/herself, heirs executors, administrators and assignees hereby fully and forever releases the State of Calliornia, its agencies, departments, officers, employees and agents from any and all liability which may accrue on account of any and all claims or causes if actions, including, but not limited to libel, slander and invasion of the right to privacy, which in any way may arise from the undersigned's participation in being pholographed, either still or videotaped, and/or recorded or the interview material.

I understand this form is a public document.

I understand this statement is given by me freely and voluntarily withoul any promises, threats, duress, or compensation and that I may cancel or amend the above decision af anytime by notifying the Warden in writing.

\begin{tabular}{l|l|l|l}
\hline \multicolumn{2}{|l|}{ INMATE'S SIGNATURE WITH STAFF WITNESSES PRESENT } & CDCR NUMBER & DATE \\
\hline INMATE'S NAME - PRINT & PRINTED NAME & INSTITUTION & HOUSING ASSIGNMENT \\
\hline STAFF WITNESS' SIGNATURE & & RANKTITLE & DATE \\
\hline
\end{tabular}




\section{Appendix I}

\section{Warden's (2011-2012) Letter of Support}

STATE OF CALIFORNIA — DEPARTMENT OF CORFECTIONS AND FEHABILITATION

EDMUND G BROWN JR, GOVERNOR

\section{DIVISION OF ADULT INSTITUTIONS \\ P.O $80 \times 942883$}

Sacramento. CA 94283-0001

August 1, 2011

San Jose State Univ's Institutional Review Board (IRB)

Attn: Alena Filip - IRB/Thesis Coordinator

San Jose State University One Washington Square

San Jose, CA 95192-0025

PROJECT TITLE: Outcomes of Recreation Therapy Interventions of Yoga and Meditation on Prison Inmates' Spiritual Well-Being

To Whom It May Concern:

This letter is to acknowledge that Deuel Vocational Institution (DVI) extends its support and intends on collaborating within the research project proposed by Ms. Kim Pham entitled: Outcomes of Recreation Therapy Interventions of Yoga and Meditation on Prison Inmates' Spiritual Well-Being.

DVI is one of thirty-three adult state prisons in California. DVI is located just outside the Tracy city limits, about an hour east of San Francisco. DVI houses approximately 3,800 inmates from nineteen Northern California counties.

The Yoga Program at our institutions was launched in June 2010. This program provides a weekly 2-hour Yoga session to mainline inmates at this facility.

As Warden, I am in support of allowing the research objectives and methods outlined in the Outcomes of Recreation Therapy Interventions of Yoga and Meditation on Prison Innates' Spiritual Well-Being program proposal to be carried out at Deuel Vocational Institution from September 1, 2011 to September 1, 2012.

If you have any questions please feel free to contact my Administrative Assistant. Lt. George Paul, at (209) 830-3851.

Sincerely,

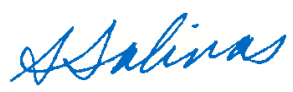

S. M. SALINAS

Warden

Deuel Vocational Institution 


\section{Appendix J}

\section{Warden's (2012-2013) Letter of Support}

DIVISION OF ADULT INSTITUTIONS

Deuel Vocational Institution

23500 Kasson Road

P.O. Box 400

Tracy, CA 95378

November 1, 2012

San Jose State Univ's Institutional Review Board (IRB)

Attn: Alena Filip - IRB/Thesis Coordinator

San Jose State University One Washington Square

San Jose, CA 95192-0025

PROJECT TITLE: Outcomes of Recreation Therapy Interventions of Yoga and Meditation on Prison Inmates' Spiritual Well-Being

TO Whom lt May Concern:

This letter is to acknowledge that Deuel Vocational Institution (DVI) extends its support and intends on collaborating within the research project proposed by Ms. Kim Pham Entitled: Outcomes of Recreation Therapy Interventions of Yoga and Meditation on Prison Inmates 'Spiritual Well-Being.

DVI is one of thirty-three adult state prisons in California. DVI is located just outside the Tracy city limits, about an hour east of San Francisco. DVI houses approximately 2,400 combined general population and reception center inmates.

The Yoga Program at our institution was launched in June 2010. This program provides a weekly 2-hour Yoga session to general population inmates at this facility.

As Warden, I am in support of allowing the research objectives and methods outlined in the Outcomes of Recreation Therapy Interventions of Yoga and Meditation on Prison Inmates' Spiritual Well-Being program proposal to be carried out at Deuel Vocational Institution from September 1, 2012 to September 1, 2013.

If you have any questions please feel free to contact my Administrative Assistant, Lt. George Paul, at (209) 830-3851.

Sincerely,

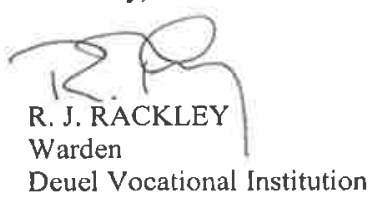




\section{Appendix K}

State of California: Department of Corrections and Rehabilitation Preliminary Review

STATE OF CALIFORNIA - DEPARTMENT OF CORRECTIONS AND REHABILITATION

EDMUND G BROWN JR, GOVERNOR

OFFICE OF RESEARCH

P.O. Box 942883

Sacramento, CA 94283-0001

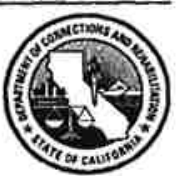

February 10,2012

Kim Hoang Pham

c/o Swapan Munshi

Deuel Vocational institution (DVI) Prison

23500 Kasson Road

Tracy, CA 95376

Dear Ms. Pham:

The California Department of Corrections and Rehabilitation (CDCR), Office of Research (OR), Research and Evaluation Branch (REB), has conducted a preliminary review of the research proposal, "Outcomes of Recreation Therapy Interventions of Yoga and Meditation on Prison Inmates' Spiritual Well-Being." This letter certifies that the CDCR is in support of this research conceptually.

While the CDCR supports the objectives of this research, the final decision to approve or deny will be contingent on the approvals of your proposal by San Jose State University's Institutional Review Board (IRB) and California's Committee for the Protection of Human Subjects. If you already received approvals, this decision is contingent on your sending us a copy of the IRB approval(s).

If you have any questions regarding this letter, please contact Teresa Isorena in the REB at (916) $323-2990$.

Sincerely,

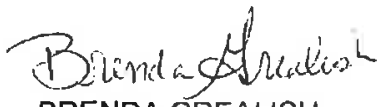

BRENDA GREALISH

Deputy Director (A)

Office of Research

cc: Swapan Munshi, Yoga Teacher, Deuel Vocational Institution Tina Fitzgerald, Chief (A), REB

Teresa Isorena, Research Program Specialist, REB 


\title{
Appendix L
}

\section{California Department of Corrections and Rehabilitation Research Advisory}

\author{
Committee Letter of Approval
}

STATE OF CALIFORNIA - DEPARTMENT OF CORRECTIONS AND REHABILITATION

EDMUND G BROWN JR, GOVERNOR

\section{OFFICE OF RESEARCH \\ P.O. Box 942883}

Sacramento, CA 94283-0001

November 14, 2012

Kim Hoang Pham

c/o Swapan Munshi

Deuel Vocational Institution

23500 Kasson Road

Tracy, CA 95376

Dear Ms. Pham,

The California Department of Corrections and Rehabilitation (CDCR), Research Advisory Committee, has completed a formal review of your research proposal and approves the project, "Outcomes of Recreation Therapy Interventions of Yoga and Meditation on Prison Inmates' Spiritual Well-Being." The purpose of your study is to determine whether program participants in the Prison Yoga Project (PYP) are experiencing outcomes of spiritual well-being. You will be conducting face-to-face semi-structured interviews with 40 research subjects, participating in the PYP interventions at Deuel Vocational Institution (DVI) General Population. Each interview is expected to take from 1.5 to 2.0 hours of an inmate's time to complete. You will also be sending a self-administered pencil and paper survey to 80 research subjects ( 40 experimental and 40 from the control group at DVI).

The Committee for the Protection of Human Subjects (CPHS) has advised us that your research proposal received approval through August 30, 2013. CDCR's approval of your project will coincide with your CPHS approval and will remain in effect until August 30, 2013.

As the Principal Investigator, it is your responsibility to comply with Department regulations and State law. Specifically, the Department Operations Manual regulations, Chapter 1. Article 19, Section 14020.7, requires that all research activities and proposals involving departmental facilities, employees, and inmates are coordinated through the Office of Research. It is also your responsibility to comply with the following guidelines:

- Ensure that the privacy and confidentiality of participants are protected per signed agreements on file at this office.

- Inform participants that all interviews are voluntary, and inform inmates of the meaning of "voluntary" (i.e., that participation will have no bearing on how staff treats them).

- Understand that access to participants will be normally permitted based on CDCR priorities and workload considerations and that all activities will be at the discretion of the institutional staff. 


\section{Appendix M}

\section{Committee for the Protection of Human Subjects Approval Letter}

\begin{tabular}{|c|c|}
\hline \multirow{2}{*}{\multicolumn{2}{|c|}{$\begin{array}{l}\text { STATE OF CALIFORNIA - HEQLTH AND HUMAN SERYICESS AGENLY } \\
\text { COMMITTEE FOR THE PROTECTION OF HUMAN SUBJECTS }\end{array}$}} \\
\hline & \\
\hline $400 R$ stiegt vainte $35 \%$ & \\
\hline Sauramento Callo:ma 95811-6213 & \\
\hline (910) 3263660 FAX (916) 3222512 & \\
\hline
\end{tabular}

October 05, 2012

Kim Pham

San Jose State University

Project Title: Outcomes of Recreation Therapy Interventions of Yoga and Meditation on Prison Inmates' Spiritual Well-Being

Project Number: 12-05-0226

Dear Ms. Pham,

The Committee for the Protection of Human Subjects (CPHS) has reviewed and approved the above new project. This approval is issued under the California Health and Human Services Agency's Federalwide Assurance \#00000681.

Pursuant to 45 CFR 46.109(e), CPHS cannot approve a project for more than one year at a time. Therefore, a project must be renewed yearly. To continue your research or data analysis, submit a Continuing Review request by your project's deadline date, August 30,2013 . If your project is not approved again (renewed), it will expire on October 4, 2013. Once a project is expired, all research, including data analysis, must cease (unless discontinuance will have an adverse impact on research subjects).

You will receive courtesy email reminders from CPHS to renew your project. It is the Principal Investigator's responsibility to submit their Continuing Review request on time and to notify CPHS of any changes in contact information,

If a project has been completed or is no longer active, it must be submitted to CPHS for Completed approval or Withdrawn approval. Please contact CPHS staff for further instruction on how to close out your project.

If you have any questions, you may call our office at (916) 326-3660 or email us at cphs-mail@oshpd.ca.gov.

Sincerely,

CPHS Administrator

(916) 326-3661

lucila.martinez@oshpd.ca.gov 


\section{Appendix N}

\section{SJSU's Human Subjects-IRB Letter of Approval}

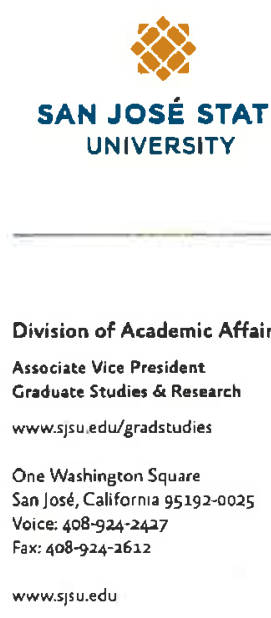

To: Kim Hoang Pham

From: Pamela Stacks, Ph.D. Associate Vice President

Graduate Studies and Research

Date: March 26, 2012

The Human Subjects-Institutional Review Board has approved your request to use human subjects in the study entitled:

"Outcomes of recreation therapy interventions of yoga and meditation on prison inmates' spiritual well-being"

This approval is contingent upon the subjects participating in your research project being appropriately protected from risk. This includes the protection of the confidentiality of the subjects' identity when they participate in your research project, and with regard to all data that may be collected from the subjects. The approval includes continued monitoring of your research by the Board to assure that the subjects are being adequately and properly protected from such risks. If at any time a subject becomes injured or complains of injury, you must notify Dr. Pamela Stacks, Ph.D. immediately. Injury includes but is not limited to bodily harm, psychological trauma, and release of potentially damaging personal information. This approval for the human subject's portion of your project is in effect for one year, and data collection beyond March 26, 2013 requires an extension request.

Please also be advised that all subjects need to be fully informed and aware that their participation in your research project is voluntary, and that he or she may withdraw from the project at any time. Further, a subject's participation, refusal to participate, or withdrawal will not affect any services that the subject is receiving or will receive at the institution in which the research is being conducted.

If you have any questions, please contact me at (408) 924-2427.

Protocol \#S1104029

cc. Susan Ross

0211 